\title{
Los acuerdos de libre comercio en América Latina desde 1990. Una evaluación de la diversificación de exportaciones
}

\author{
Alfonso Dingemans y César Ross
}

Resumen

Se revisa la afirmación, hasta ahora no sometida a verificación, de que los acuerdos de libre comercio (ALC) firmados por los países latinoamericanos — fundamento de sus estrategias de integración económica internacional desde 1990- han permitido diversificar sus exportaciones y aumentar el número de socios comerciales. La evidencia obtenida de la Base de datos estadísticos sobre el comercio de mercaderías (COMTRADE), sugiere que gran parte del crecimiento exportador en la región ha ocurrido en el margen intensivo, no en el extensivo. La expansión hacia nuevos productos y socios comerciales ha sido limitada, según los índices de concentración. La apuesta de América Latina de diversificar exportaciones a partir de ALC sin estrategias más integrales — debido a un concepto estático de ventajas comparativas - generó resultados exiguos. Por consiguiente, los gobiernos debieran adoptar un enfoque más dinámico respecto de las ventajas comparativas e implementar políticas más activas. Finalmente, se plantean algunas preguntas para futuras investigaciones.

PALABRAS CLAVE

CLASIFICACIÓN JEL

AUTORES
Libre comercio, tratados, política comercial, diversificación de las exportaciones, evaluación, estadísticas comerciales, América Latina

F13, N16, O25

Alfonso Dingemans es investigador posdoctoral y académico del Instituto de Estudios Avanzados (IDEA), Universidad de Santiago de Chile. alfonso.dingemans@usach.cl

César Ross es profesor titular y académico del Instituto de Estudios Avanzados (IDEA), Universidad de Santiago de Chile; y director del Doctorado en Estudios Americanos de dicha Universidad.cesar.ross@usach.cl 


\section{I}

\section{Introducción}

Si bien en las economías de América Latina ${ }^{1}$ se había adoptado una actitud escéptica respecto de las ventajas y los beneficios del (libre) comercio en el período de la belle époque (1940-1975), la devastadora crisis de la deuda en la década de 1980 hizo que la atención se volcara al descuidado sector exportador. Los países tenían una urgente necesidad de divisas para pagar sus cuantiosas deudas y su supervivencia económica estaba determinada principalmente por la capacidad exportadora (Edwards, 1995; Ffrench-Davis, Muñoz y Palma, 1996; Thorp, 1998; Bulmer-Thomas, 2003).

Fueron muchos los motivos que condujeron a una gran cantidad de países de la región a adoptar una reforma económica "promercado", basada en un paquete de 10 medidas propuesto y utilizado por varias instituciones con sede en Washington - conocido como el Consenso de Washington (Williamson, 1990)_, aunque algunos académicos cuestionan hasta qué punto las reformas implementadas eran realmente promercado (Edwards, 2010). El consenso promovía la idea del libre comercio y destacaba la necesidad de contar con un sector exportador sólido, además de plantear la apertura a la competencia internacional como la única forma de eliminar a las empresas ineficientes. Se suponía que si se impulsaba el sector exportador se obtendrían importantes repercursiones en el resto de la economía (esta idea ya aparece en la obra de Adam Smith), debido a lo cual se pensaba que existía un estrecho vínculo entre el incremento de las exportaciones (maximizado en virtud del libre comercio) y el crecimiento económico. No obstante, las investigaciones han demostrado que el libre comercio por sí solo no es suficiente e incluso puede llegar a ser perjudicial para dicho crecimiento (Taylor, 1991; Rodríguez y Rodrik, 1999; Van den Berg

$\square$ Los autores agradecen los valiosos comentarios de un árbitro anónimo. Agradecen además el apoyo financiero del Proyecto de Mejoramiento de la Calidad y Equidad de la Educación Superior (MECESUP UCH 0602) para becas de posdoctorado del Doctorado en Estudios Americanos de la Universidad de Santiago de Chile. Finalmente, expresan que todos los errores u omisiones son de su responsabilidad.

${ }^{1}$ En este artículo, cuando se hace referencia a las economías de América Latina, se incluyen las 11 economías más grandes con respecto al producto interno bruto (PIB): Argentina, Bolivia (Estado Plurinacional de), Brasil, Chile, Colombia, Ecuador, México, Paraguay, Perú, Uruguay y Venezuela (República Bolivariana de). y Lewer, 2007; Mejía, 2011). Los gobiernos debieran adoptar una actitud más activa e influir en "el tipo y la secuencia de las exportaciones cuando un país se esfuerza por producir bienes más avanzados, agregándoles valor" (Todaro y Smith, 2006, pág. 441).

Es decir, para que la cadena causal de libre comercio, expansión de las exportaciones, crecimiento económico y desarrollo económico ${ }^{2}$ funcione, una economía debe exportar productos de mayor valor agregado, algo que debiera lograrse mediante la implementación de políticas de gobierno activas. Es necesario cambiar el énfasis de la estrategia de posicionamiento económico internacional de los países, pasando de un enfoque tradicional, ricardiano (estático o pasivo), respecto de las ventajas comparativas — que se reciben de forma no intencionada-, a otro más dinámico donde se aplican políticas industriales o de gobierno activas con el fin de provocar este "cambio estructural" necesario para generar ventajas comparativas intencionales, aunque sin dejar por completo de lado el libre comercio (Agosin, 2006, pág. 2; Mejía, 2011, pág. 36). La experiencia asiática ha demostrado que las políticas comerciales y el libre comercio no son necesariamente incompatibles y que incluso pueden ser complementarios (Fishlow y otros, 1994). Dicho de otro modo, lo que importa en el desarrollo económico es la calidad del crecimiento de las exportaciones.

Esto también significa que la diversificación de las exportaciones, idealmente mediante la inclusión de productos de mayor valor agregado, es una buena referencia para evaluar el desempeño de las exportaciones de una economía y alcanzarla es de hecho una "búsqueda urgente" (Leipziger, 2009, pág. xi). En este artículo, por diversificación se entenderá una mayor variedad de productos exportados a un mayor número de mercados extranjeros, con —a la vez- una distribución más pareja entre dichos mercados. Esta última condición habitualmente no forma parte de la definición de diversificación,

\footnotetext{
2 Aquí el desarrollo económico se define como un proceso de transformación estructural en virtud del cual los países pasan de producir "bienes de países pobres" a producir "bienes de países ricos" (Hesse, 2008, pág. 1) o, en otras palabras, dejan de producir bienes con poco valor agregado y comienzan a producir bienes con mucho valor agregado.
} 
pero en este estudio se la considera esencial, ya que sería un error, por ejemplo, afirmar que las exportaciones de un país están más diversificadas cuando logran acceder a 10 nuevos mercados, en circunstancias de que un solo mercado extranjero sigue representando el $95 \%$ del total de dichas exportaciones.

A la luz de los bien conocidos corolarios de la teoría clásica del comercio internacional, puede resultar sorprendente que se defienda la idea de diversificación por sobre la de especialización. Sin embargo, se pueden identificar tres ventajas en favor de la diversificación (Mejía, 2011): i) funciona como una estrategia de cobertura de riesgos que añade más estabilidad a los ingresos provenientes de las exportaciones; ii) cuando se dan otras condiciones institucionales puede desencadenar este "cambio estructural", y iii) si ese cambio estructural resulta exitoso, puede mejorar el crecimiento económico sostenido. Según Agosín (2006), a largo plazo, y siempre que ocurra el mencionado cambio estructural, la diversificación puede lograr que una economía aproveche los beneficios de una "especialización más diversificada". Por lo tanto, la cadena causal aquí propuesta es: (libre comercio), crecimiento de las exportaciones, "diversificación" de las exportaciones, desarrollo económico y crecimiento económico (el libre comercio es un elemento complementario, no una condición suficiente).

De acuerdo con la definición expresada en el presente artículo, se deben por tanto tomar en cuenta dos dimensiones. En primer lugar se debe establecer una diferencia entre crecimiento de las exportaciones (Brenton y Newfarmer, 2009, pág. 112) en el margen extensivo (aumento de los productos existentes dirigidos a mercados existentes) y crecimiento de las exportaciones en el margen intensivo (expansión de nuevos productos dirigidos a mercados existentes, productos existentes dirigidos a nuevos mercados o nuevos productos dirigidos a nuevos mercados). En segundo término, y como complemento de la primera medida, se deben calcular los índices de concentración (Samen, 2010).

Pese a los argumentos en favor de las políticas de gobierno activas, la práctica en América Latina ha sido algo diferente, con gobiernos que muestran una marcada preferencia por las ventajas comparativas estáticas. A partir del fracaso de la tercera Conferencia Ministerial de la Organización Mundial del Comercio, realizada en 1999 en Seattle, Estados Unidos de América, y el estancamiento de la Ronda de Doha, los países de la región han adoptado como principal vehículo de integración económica internacional los acuerdos de libre comercio (acuerdos bilaterales o multilaterales de comercio establecidos en virtud del artículo XXIV del Acuerdo General sobre Aranceles Aduaneros y Comercio (GATT) como excepciones a la cláusula de nación más favorecida).

La amplia popularidad de los acuerdos de libre comercio (ALC) a nivel mundial derivó en que Bhagwati (1995) hablara, quizás injustamente, de un "encaprichamiento" por dichos acuerdos. Entre sus diversos efectos positivos se incluyen la reducción de los aranceles y las barreras no arancelarias, el incremento del acceso a los mercados, el mejoramiento del nivel de competitividad, la promoción del aumento de la inversión extranjera directa (IED), el descenso de los niveles de incertidumbre y riesgo, y la creación de empleo gracias al crecimiento de las exportaciones (Lynch, 2010, págs. 2-9). Además, numerosos académicos y encargados de formular políticas se muestran optimistas respecto de la repercusión de estos acuerdos en la diversificación de las exportaciones, lo que denominaremos el nexo entre los ALC y la diversificación de las exportaciones.

Por lo tanto, parecería que los ALC son ejemplos de políticas activas diseñadas para lograr una mayor diversificación de las exportaciones. Esto es cierto, pero solo en parte. Al negociar un ALC, los gobiernos pretenden diversificar las exportaciones. No obstante, hay dos salvedades. Primero, ¿qué ocurre si los ALC son una mera confirmación de vínculos económicos ya existentes? ¿El reemplazo de prácticas informales por otras formales puede realmente considerarse una política activa? Un ALC es simplemente la infraestructura para el comercio. Por analogía, cuando un gobierno construye un puente, generalmente no utiliza la política para tratar de incidir en el tipo de gente que lo va a usar. De manera similar, muchos gobiernos de América Latina piensan que su tarea termina con la firma de un ALC (el puente) y después no se preocupan por los productos que se exportan. Este enfoque coincide totalmente con la formulación ortodoxa de políticas, en la que el gobierno es responsable de proporcionar la infraestructura básica, pero el sector privado determina cuándo y cómo se utiliza (obviamente, dentro de los límites legales). La idea de que los ALC pueden, por sí mismos, dar lugar a la diversificación de las exportaciones concuerda con esta filosofía.

De hecho, si existiera un nexo entre los ALC y la diversificación de las exportaciones, la operación del mecanismo de precios sería una condición suficiente para provocar un cambio en la estructura productiva de una economía y el papel del gobierno en lo que respecta al desarrollo económico se vería reducido al suministro de una infraestructura adecuada, sin interferir en su utilización. en cuyo caso serían innecesarias las discusiones respecto de la diferencia entre las ventajas 
comparativas estáticas y las dinámicas, y de los límites entre el Estado y el mercado. En consecuencia, la evaluación del impacto de los ALC en la diversificación de las exportaciones es fundamental para el desarrollo, tanto en términos teóricos como prácticos. Finalmente, si se probara que una estrategia de laissez-faire conduce al desarrollo económico, la supuesta necesidad de políticas industriales activas sería exagerada.

Resulta sorprendente que haya tan pocas investigaciones sobre este tema, ya que la mayoría de los estudios se centran en el nexo entre el crecimiento económico y el crecimiento de las exportaciones (Mejía, 2011; Volpe y Milena, 2009). Por lo tanto, ha llegado el momento de comenzar a analizar de manera sistemática hasta qué punto los ALC han propiciado la diversificación de las exportaciones (la "calidad" del crecimiento de las exportaciones) en América Latina, a fin de determinar cómo los gobiernos pueden o deberían tratar de influir en la actividad exportadora, y posteriormente efectuar un debate más amplio sobre los límites entre el Estado y el mercado.

El propósito de este artículo es contribuir a una nueva agenda de investigación en que se realice una evaluación crítica de las estrategias de inserción económica de América Latina según la diversificación de las exportaciones y no de su crecimiento. Debido a la dificultad para desentrañar y aislar las distintas causalidades en juego, la primera tarea consiste en describir y realizar una evaluación preliminar de la incidencia de los ALC en la diversificación de las exportaciones, dada su popularidad como herramienta de política. La intención en este trabajo no es simplificar el tema reduciéndolo a un único factor; se trata solo de un primer paso que en una etapa posterior permitirá incluir otras variables contingentes, como los términos de intercambio. En investigaciones aún por hacerse se podría examinar la economía política (internacional) de diversificación, es decir, investigar cómo los ganadores y perdedores de la liberalización comercial influyen en el proceso de formulación de políticas que aumentan o dificultan la diversificación, para lo cual se requerirán más estudios de caso similares al de Mejía (2011). Las investigaciones también podrían centrarse en vías alternativas para lograr la diversificación de las exportaciones, por ejemplo, mediante la IED ${ }^{3}$. De modo similar, otros instrumentos para la inserción económica internacional de América

\footnotetext{
${ }^{3}$ La inversión extranjera directa (IED) es un tema explícito de los acuerdos bilaterales de comercio, pero no se aborda porque va más allá del alcance de este artículo.
}

Latina, como las actividades de promoción de las exportaciones, ameritan una investigación más profunda sobre sus efectos en la diversificación de las exportaciones. Empero, los hallazgos preliminares sobre el tema de los autores de este estudio, que ya fueron publicados, son desalentadores.

En este artículo los autores se limitan a realizar una evaluación exploratoria y cuantitativa de la relación entre los ALC y el comportamiento de las exportaciones en cuanto a la diversificación, a partir de la Base de datos estadísticos sobre el comercio de mercaderías (COMTRADE). Los resultados muestran que los ALC han tenido poca repercusión en la estructura productiva del sector exportador (sobre todo con respecto a su capacidad para producir nuevos bienes exportables) y en su expansión a nuevos mercados. Se trata de acuerdos que no crean nuevos modelos o estructuras, sino que más bien confirman los que ya existen. Esta falta de cambio estructural se ve confirmada, además, por unos índices de concentración bastante estables.

El primer lugar, esto significa que el optimismo actual respecto del nexo entre los ALC y la diversificación es inapropiado - y el argumento en favor de las políticas industriales en gran parte correcto-, ya que cualquier diversificación (si existiere) sería consecuencia de procesos anteriores, o sea, procesos previos e independientes de la firma de los acuerdos. Esto se observa más claramente en el caso de Chile, donde el proceso de diversificación tuvo lugar en las décadas de 1970 y 1980, más que en los últimos 20 años. Por lo tanto, los ALC prácticamente no tuvieron ningún efecto en la estructura productiva de las exportaciones chilenas. Además, como se mostrará más adelante, su efecto en la creación de nuevos mercados ha sido limitado, ya que los países que los han firmado ya tenían estrechos vínculos económicos (pueden considerarse "mercados naturales") y estos acuerdos solo fueron un reconocimiento formal a nivel estatal de las prácticas informales que ya existían. No obstante, no se puede descartar de plano la existencia de un vínculo entre los ALC y la diversificación de las exportaciones, debido al limitado alcance y propósito de este artículo, puesto que el efecto de cada acuerdo depende de los "fundamentos" (las condiciones que cada país necesita que se den para concretar una diversificación de las exportaciones) de las partes signatarias (Hausmann, Hwang y Rodrik, 2007). Por todo lo expuesto, se necesita contar con más pruebas caso por caso.

En segundo término, los hallazgos de este trabajo respaldan la adopción de una postura más moderada respecto de los efectos previstos de los 
ALC. Estos acuerdos no garantizan un crecimiento de las exportaciones de alta calidad, ni sustituyen las políticas industriales y sociales (Malvasio, 2006). En otras palabras, si bien son una pieza fundamental de la arquitectura del comercio internacional, su mera existencia no supone necesariamente su utilización. Además, aunque los ALc tuvieran un efecto diversificador de las exportaciones, la pregunta sigue siendo si los incentivos que incluyen superarían a otros incentivos, como por ejemplo, los elevados precios de los productos básicos (tal es el caso de China), que favorecen las exportaciones de estos productos. En ese escenario, una política industrial más activa podría mitigar la influencia de esos otros incentivos. En este estudio se considera que el mercado por sí mismo no puede lograr el desarrollo económico y que las políticas industriales siguen siendo una herramienta importante (Rodrik, 2011; Chang, 2012). Futuras investigaciones deberían ayudar a identificar mejores políticas o instrumentos para fortalecer el vínculo entre el sector exportador y el desarrollo económico.
El presente artículo está organizado en cuatro secciones. En la sección II se muestra la importancia de las exportaciones en las estrategias de desarrollo de los países de América Latina, y en particular de los ALC en sus estrategias de inserción económica internacional. En la sección III se evalúa la calidad del crecimiento de las exportaciones en la muestra de países. Con ese propósito, se presenta la metodología seguida y se destacan los cambios observados en la composición de los socios comerciales de los países y sus exportaciones. A continuación se muestra el crecimiento de las exportaciones en los márgenes extensivo e intensivo. Para completar la evaluación de la diversificación de las exportaciones, se efectúa un resumen de cuatro índices de concentración (para países y productos). Luego se estima hasta qué punto los ALC han sido perjudiciales o no para lograr el acceso a nuevos mercados y promover un cambio en la estructura productiva (exportación de nuevos productos). Finalmente, en la sección IV se entregan las conclusiones, con un llamado a realizar nuevas investigaciones.

\section{II \\ La integración económica internacional de América Latina mediante los acuerdos de libre comercio (ALC)}

Los años ochenta fueron difíciles para América Latina. Desde la primera crisis del petróleo a comienzos de la década de 1970 (si no antes), las economías de la región comenzaron a ir cuesta abajo. Entre otros factores, esto se debió a la estrategia de desarrollo orientada al interior-conocida como industrialización por sustitución de importaciones (ISI) y adoptada en un principio por la región en respuesta a la Gran Depresión-, cuya tendencia contraria a las exportaciones planteaba graves dificultades para el financiamiento de las importaciones de bienes de capital, un componente esencial de dicha estrategia de desarrollo (Ffrench-Davis, Muñoz y Palma, 1996). Además, aunque era necesaria para la paz social, la excesiva expansión del Estado (tanto en términos de su función como de su peso relativo en la economía) volvió prácticamente imposible el equilibrio fiscal. Los petrodólares y eurodólares que ingresaron a las economías de América Latina resultaron ser una ilusión, ya que solo ofrecieron un alivio temporal a corto plazo: ante la ausencia de reformas estructurales no lograron evitar el colapso, porque los préstamos en algún momento debían pagarse. Lo que es peor aún, estos flujos de capital se destinaron al consumo más que a la inversión y, dada la baja competitividad del sector exportador, cualquier incremento repentino del costo de los préstamos dificultaría mucho el cumplimiento de los pagos. Cuando la tasa de interés de los Estados Unidos de América se disparó en junio de 1982 y causó una desviación de los flujos de capital, el Gobierno de México incurrió en cesación de pagos. El pánico financiero se extendió a toda la región dejando gravemente afectadas a sus economías.

La interpretación ortodoxa de los hechos culpó de los males de América Latina a la excesiva presencia del Estado y se propusieron medidas para liberar las fuerzas del mercado bajo el eslogan "más mercado 
y menos Estado" (medidas que Williamson, 1990, denominaría el Consenso de Washington). Por diversas razones que no se detallan en el presente artículo (véanse, por ejemplo, Edwards, 1995 y 2010; Yergin y Stanislaw, 1998; Thorp, 1998; Stokes, 2001), a comienzos de la década de 1990, los países de América Latina, con muy pocas excepciones, adoptaron —al menos nominalmente- las orientaciones de política del Consenso de Washington. Aún se debate hasta qué punto las reformas económicas de los años noventa pueden considerarse ortodoxas y algunos académicos incluso cuestionan si pueden catalogarse como tales (Edwards, 2010). Sin embargo, los gobiernos redujeron sus aranceles en promedio, aunque no necesariamente de manera global, y abrieron sus economías a la competencia internacional, uniéndose así a la ola de globalización basada en un modelo de ventajas comparativas estáticas, ya que — según Rodrik (2011) — la política industrial se había vuelto un tabú.

Empero, los resultados no siempre fueron positivos. Ante la ausencia de redes de seguridad social y políticas que mejoraran la movilidad (como planes de reeducación), a la "desindustrialización", resultado del aumento de la competencia, le siguieron el subempleo y el desempleo estructural, las precarias condiciones económicas y sociales, y el crecimiento del sector informal. Las exportaciones se vieron limitadas sobre todo a productos básicos agrícolas y minerales con poco valor agregado, sofisticación o innovación tecnológica.

La imposibilidad del Consenso de Washington de resolver los problemas políticos, económicos y sociales de América Latina — porque sería injusto afirmar que las reformas introdujeron estos problemas en la regiónterminó provocando un "giro a la izquierda" (Castañeda, 2006). Los gobernantes de tendencia más izquierdista que asumieron el poder mejoraron, cambiaron o directamente reemplazaron muchas de las reformas. Sin embargo, las exportaciones continuaron siendo la piedra angular de sus estrategias de desarrollo, más allá de la aversión que algunos de estos gobernantes sentían por el pensamiento económico ortodoxo. Incluso reconocen la importancia de las exportaciones Hugo Chávez, presidente de la República Bolivariana de Venezuela y férreo defensor del anticapitalismo, y las administraciones de Kirchner y Fernández en la Argentina — que propusieron políticas económicas populistas más tradicionales, como las definieron Dornbusch y Edwards (1991).

Los ALC parecerían ser la manera más óptima de mejorar el crecimiento de las exportaciones, sobre todo teniendo en cuenta el fracaso de las rondas de negociaciones multilaterales de la Organización Mundial del Comercio (OMC). El propio Chávez sueña con un bloque de libre comercio bolivariano, exclusivo para los países de América Latina. La firma de ALC es proclamada por los presidentes y por los medios de comunicación como el vehículo ideal para promover el libre comercio, impulsar las exportaciones y obtener acceso y prestigio en el escenario político y económico internacional. Se trata de acuerdos fundamentales para la actual estrategia de posicionamiento económico internacional de América Latina y, por lo tanto, se entiende que gobernantes y académicos depositen en ellos muchas expectativas.

Pese al mencionado "giro a la izquierda", los gobiernos se muestran optimistas (aunque no complacientes) respecto del crecimiento de las exportaciones de la región y específicamente con respecto al nexo entre los ALC y la diversificación de las exportaciones. Si se echa un vistazo al debate público se confirma esta idea. Por ejemplo, Barbara Weisel, asistente del representante comercial estadounidense para el Asia y el Pacífico, dijo que el ALC entre los Estados Unidos de América y Malasia creará nuevas oportunidades y apoyará el objetivo del país asiático de diversificar sus exportaciones e impulsar el comercio de mayor valor agregado (Bernama, 2007). Cuando se le pidió su opinión sobre el futuro ALC entre China y el Perú, el economista Michael Pettis, de la Universidad de Beijing, manifestó que la actual situación de la economía china, que está virando hacia la importación de manufacturas, impulsará al Perú a diversificar sus exportaciones (La Primera, 2012). Según un informe de una consultora privada, no hay prácticamente ninguna duda de que, a largo plazo, el ALC entre China y la Asociación de Naciones del Asia Sudoriental (ASEAN) ayudará a mejorar la diversificación de las exportaciones (BMI View, 2010). En una declaración conjunta de los presidentes Piñera y Obama con ocasión de la visita de este a Chile, se subrayó que en los siete años transcurridos desde que entró en vigencia el Tratado de Libre Comercio entre los Estados Unidos de América y Chile, no solo han mejorado las condiciones para el intercambio de bienes y servicios, sino que se han abierto nuevas oportunidades de negocios, lo que condujo a la diversificación de productos (Ministerio de Relaciones Exteriores de Chile, 2011) En el libro publicado por la Dirección General de Relaciones Económicas Internacionales (DIRECON) de Chile para conmemorar los 20 años de negociaciones comerciales del país, los autores concluyen que entre 1990 y 2010 se ha verificado una considerable diversificación tanto de los productos exportados por Chile como de sus socios 
comerciales (DIRECON, 2010, pág. 11) ${ }^{4}$. Finalmente, y a nivel más teórico, Volpe y Milena (2009, págs. 4-5) se refieren a un creciente consenso en la literatura especializada respecto del vínculo entre los niveles arancelarios y la capacidad de una economía para exportar nuevos productos; la mayoría de los países aplican un modelo ricardiano según el cual se predice que la reducción de las barreras arancelarias aumenta la variedad de productos exportados.

Si la mitad de estas apreciaciones fueran ciertas, la popularidad de los ALC no sería para nada sorprendente, pero el problema (posible, al menos) es que estas afirmaciones no están respaldadas por pruebas. Por consiguiente, es necesario evaluar si los ALC realmente propician la diversificación de las exportaciones o si estamos ante un caso de "mucho ruido y pocas nueces". En este artículo se tratará de elaborar una respuesta preliminar y de sugerir áreas para futuras investigaciones que puedan proporcionar un análisis más profundo.

En primer lugar, cabe preguntarse si los ALC son realmente tan populares. Hasta enero de 2012, la OMC había recibido unas 511 notificaciones de acuerdos de comercio regional, el $90 \%$ de los cuales correspondía a ALC y acuerdos de comercio preferencial ${ }^{5}$. De estos, estaban vigentes unos 319 acuerdos. Según el

\footnotetext{
${ }^{4}$ La DIRECON, dependencia del Ministerio de Relaciones Exteriores de Chile, es responsable, entre otras cosas, de planificar y ejecutar la política económica exterior del país y de negociar los acuerdos de libre comercio.

5 Véase [en línea] http://www.wto.org/english/tratop_e/region_e/ region_e.htm
}

Sistema de Información sobre Comercio Exterior de la Organización de los Estados Americanos (OEA $)^{6}$, hay 64 ALC, 3 acuerdos marco y 33 acuerdos de comercio preferencial vigentes entre sus Estados miembros, lo que se resume en el cuadro $1^{7}$.

Chile y México son los países que han firmado más ALC, al tiempo que la República Bolivariana de Venezuela y Colombia representan más del $50 \%$ de todos los acuerdos de comercio preferencial suscritos (véase el cuadro 1). Todos los acuerdos de comercio preferencial firmados por los países de la región son con países asociados en América del Sur y Centroamérica, mientras que algunos de los ALC son de naturaleza intercontinental. Los socios comerciales tradicionales en América Latina, América del Norte y Europa, representan alrededor del $60 \%$ de todos los acuerdos firmados y los socios no tradicionales en Asia y Oceanía representan el $30 \% 8$. Esto indica que en la región los ALC vienen a confirmar o profundizar vínculos comerciales ya existentes en lugar de abrir otros nuevos.

Colombia, México y, sobre todo, Chile son los países que han firmado más ALC con países de otros continentes. En el otro extremo se encuentra la República

\footnotetext{
6 Véase [en línea] http://www.sice.oas.org/agreements_e.asp

${ }^{7}$ Se incluyen los ALC y los acuerdos de comercio preferencial firmados por los miembros del Mercado Común del Sur (MERCOSUR) para cada uno de los Estados correspondientes. Así, los cuatro ALC firmados por el MERCOSUR representan un total de 16 ALC en el cuadro 1 (cuatro para cada miembro) y el acuerdo de comercio preferencial firmado por el bloque comercial se cuenta cuatro veces (una por cada miembro). ${ }^{8}$ Los dos ALC firmados por Chile y México con la Unión Europea se cuentan como dos ALC y no como 27 acuerdos independientes con cada uno de los 27 Estados miembros de la Unión Europea.
} vigentes, según número de acuerdos y de socios comerciales

\begin{tabular}{|c|c|c|c|c|c|c|}
\hline País & $\begin{array}{c}\text { Acuerdos de } \\
\text { libre comercio } \\
\text { (ALC) } \\
\text { (Cuenta simple) }\end{array}$ & $\begin{array}{c}\text { Acuerdos de } \\
\text { comercio } \\
\text { preferencial } \\
\text { (Cuenta simple) }\end{array}$ & $\begin{array}{c}\text { Total } \\
\text { de } \\
\text { acuerdos }\end{array}$ & $\begin{array}{c}\text { Acuerdos de } \\
\text { libre comercio } \\
\text { (ALC) } \\
\text { (Cuenta por país) }\end{array}$ & $\begin{array}{c}\text { Acuerdos de } \\
\text { comercio } \\
\text { preferencial } \\
\text { (Cuenta por país) }\end{array}$ & $\begin{array}{c}\text { Total de } \\
\text { socios } \\
\text { comerciales }\end{array}$ \\
\hline Argentina & 4 & 6 & 10 & 4 & 8 & 12 \\
\hline Bolivia (Estado Plurinacional de) & 2 & 1 & 3 & 5 & 1 & 6 \\
\hline Brasil & 4 & 5 & 9 & 4 & 7 & 11 \\
\hline Colombia & 5 & 6 & 11 & 10 & 25 & 35 \\
\hline Ecuador & 0 & 4 & 4 & 0 & 7 & 7 \\
\hline México & 13 & 4 & 17 & 44 & 6 & 50 \\
\hline Paraguay & 4 & 3 & 7 & 4 & 5 & 9 \\
\hline Perú & 10 & 1 & 11 & 14 & 1 & 15 \\
\hline Uruguay & 5 & 4 & 9 & 5 & 6 & 11 \\
\hline Venezuela (República Bolivariana de) & 0 & 10 & 10 & 0 & 29 & 29 \\
\hline
\end{tabular}


Bolivariana de Venezuela, que solo firmó acuerdos de comercio preferencial.

En los países de América Latina se ha optado más por los ALC que por los acuerdos de comercio preferencial. De hecho, el último acuerdo de comercio preferencial de los países latinoamericanos fue firmado en 2004. Hasta la fecha, los países o bloques comerciales de la región han firmado 39 ALC y 29 acuerdos de comercio preferencial. En comparación, antes de 1997, menos del $25 \%$ de todos los acuerdos comerciales suscritos por países de América Latina eran ALC. Esto demuestra que los países latinoamericanos buscan una mayor integración económica. Sin embargo, aún se observan algunas señales de proteccionismo, como por ejemplo, en las últimas medidas implementadas por la presidenta Fernández en la Argentina.
En suma, los ALC se presentan como un instrumento cada vez más importante para lograr la integración económica. No obstante, la distribución geográfica de los socios comerciales en estos acuerdos no es para nada satisfactoria, ya que se firman principalmente con los socios tradicionales de la región, por lo que constituyen una mera formalización de los vínculos ya existentes con mercados naturales y no crean otros nuevos. Además, en concordancia con la filosofía en que se basa el Consenso de Washington, los ALC se consideran una finalidad en sí mismos y no un elemento de una política comercial activa y más abarcadora con que se procuraría promover las exportaciones de productos de mayor valor agregado. Por lo tanto, actualmente los países emplean una estrategia construida en torno de ventajas comparativas estáticas. Estos puntos se abordarán más en profundidad en las siguientes secciones.

\section{III}

\section{Crecimiento de las exportaciones en América Latina: ¿diversificación o concentración?}

Tras exponer sobre la importancia y las características de los acuerdos comerciales (ya sean ALC o acuerdos de comercio preferencial) adoptados como parte de las estrategias de inserción económica internacional de América Latina, en esta sección se analizan los resultados de dichas estrategias mediante la revisión de tres áreas. En primer lugar, se presenta un detallado análisis del crecimiento de las exportaciones en América Latina desglosado en los márgenes extensivo e intensivo. A continuación, se evalúa si los países de la región han mostrado una tendencia a la diversificación o a la concentración en lo que atañe a sus socios comerciales y los productos exportados. En tercer término, se investiga si los ALC han tenido algún efecto destacado en los procesos de diversificación y concentración. Antes de responder a estas interrogantes, se planteará la metodología utilizada en este trabajo.

\section{Metodología}

Para examinar las interrogantes planteadas se utiliza información proveniente de COMTRADE, la más completa y detallada base de datos sobre la materia ${ }^{9}$. No obstante,

${ }^{9}$ Véase [en línea] http://comtrade.un.org/db se debe reconocer que las estadísticas comerciales pueden ser susceptibles de errores y discrepancias, y que los datos disponibles en la COMTRADE no son la excepción.

Para garantizar la homogeneidad de los datos en la muestra de países, aquí se utiliza la segunda revisión de la Clasificación Uniforme para el Comercio Internacional (CUCI), de 1976. En esta clasificación, los productos se agrupan en 10 títulos con códigos de un dígito y luego se desglosan hasta que se identifican 1.924 productos distintos usando códigos de cinco dígitos (Naciones Unidas, 1975, pág. vii). Cuanto más dígitos se incluyen, más productos distintos se identifican. Sin embargo, la realización del análisis cuantitativo en el nivel más detallado (de cinco dígitos) puede no ser de utilidad para identificar nuevas exportaciones que apuntan a la diversificación de productos. Por ejemplo, en el nivel de cinco dígitos, la carne con hueso y la carne deshuesada se consideran dos productos distintos, mientras que se debieran agrupar para los efectos del presente análisis. Volpe y Milena (2009) usaron datos a nivel de 10 dígitos del Sistema Armonizado de Designación y Codificación de Mercancías (una alternativa a la CUCI) y sus conclusiones respecto de la capacidad de la reducción de aranceles para promover la diversificación de las exportaciones son demasiado optimistas, ya que es discutible si su nivel de precisión identifica productos 
significativamente distintos. El propósito del estudio que aquí se efectúa es encontrar un equilibrio entre la precisión excesiva y el agrupamiento excesivo, ya que ambos tendrían un efecto negativo en los resultados. Evenett y Venables (2002) propusieron una lista simple de 71 productos definidos a nivel de dos dígitos, pero con un umbral de 50.000 dólares por cada línea de productos. En otras palabras, las exportaciones de productos específicos por menos de 50.000 dólares no se contabilizaron y, por lo tanto, si las exportaciones aumentaron, por ejemplo, de 30.000 dólares a 500.000 dólares, se consideró que ese incremento ocurrió en el margen extensivo. Para la presente investigación se definió la lista de productos a nivel de dos dígitos usando la cucı Revisión 2 y se aplicó un umbral de 50.000 dólares por producto. Con el fin de medir el cambio en los socios comerciales de la región se usó un umbral de 500.000 dólares por país y un mínimo de 10 productos $^{10}$.

Como puntos de medición en el tiempo se eligieron los años 1990 y 2008. El primero porque antecede a la actual ola de ALC y el segundo porque es el año más reciente para el que se dispone de datos, tomando en

${ }^{10}$ De hecho, en este artículo se repiten los análisis a nivel de cinco dígitos ( $\sin$ límite) y, si bien por cuestiones de espacio no se pueden publicar los resultados, se está en condiciones de afirmar que los resultados básicos aquí expuestos también se vieron respaldados en ese nivel de detalle, por lo que pueden considerarse sólidos. Los resultados a nivel de cinco dígitos pueden solicitarse a los autores.

CUADRO 2

Clasificación Uniforme para el Comercio Internacional (cucl), 1976 (Revisión 2), códigos de un dígito

\begin{tabular}{cl}
\hline $\begin{array}{c}\text { Títulos de } \\
\text { las secciones }\end{array}$ & \multicolumn{1}{c}{ Descripción } \\
\hline 0 & Productos alimenticios y animales vivos \\
1 & Bebidas y tabaco \\
2 & Materiales crudos no comestibles, excepto los \\
& combustibles \\
3 & Combustibles y lubricantes minerales y productos \\
& conexos \\
4 & Aceites, grasas y ceras de origen animal y vegetal \\
6 & Productos químicos y productos conexos, n.e.p. \\
7 & Artículos manufacturados, clasificados \\
8 & Maquincipalmente según el material \\
9 & Artículos manufacturados diversos \\
& Mercancías y operaciones no clasificadas en otro rubro
\end{tabular}

Fuente: Base de datos estadísticos sobre el comercio de mercaderías (COMTRADE).

n.e.p. $=$ no especificados en otra parte. cuenta la necesidad de promediar los datos. A saber, a fin de controlar por las exportaciones puntuales, ya sea en términos de tipo de producto o mercado de destino, se promediaron los datos de tres puntos en el tiempo. De este modo, las cifras para 1990 y 2008 en realidad son los promedios de 1989, 1990 y 1991; y de 2007, 2008 y 2009 , respectivamente.

Al elegir 2008 para el presente análisis se deben descartar todos los acuerdos que entraron en vigencia después de ese año. La gran mayoría de los ALC se firmaron antes de 2006, lo que deja tiempo suficiente para que sus posibles efectos puedan ser captados por los datos consignados en este estudio. Lo mismo vale para los acuerdos de alcance parcial.

La interpretación de los datos de estos años plantea ciertas dificultades, ya que la caída de la "Cortina de Hierro" provocó el surgimiento de varios países nuevos a comienzos de la década de 1990. La Unión Soviética dejó de existir y se establecieron nuevos Estados independientes, como Croacia. Además, en 1990 se decidió separar los datos de Bélgica y Luxemburgo en la COMTRADE (hasta entonces habían sido tratados como una entidad). Como cada país tiene un código de clasificación distinto, estos acontecimientos condujeron de manera artificial a la ganancia o pérdida de socios comerciales para la selección de países de América Latina aquí considerada, independientemente de sus intenciones o acciones. Pese a ello, tratar de calcular de manera retroactiva el PIB de los países que anteriormente conformaban Yugoslavia, Checoslovaquia o la Unión Soviética sería una tarea difícil y arbitraria, además de que resultaría imposible saber qué productos se exportaron y a qué destinos. Ante las dificultades provocadas por la falta de datos precisos, se decidió mantener los códigos originales de los países. En consecuencia, en la información que se presenta a continuación se deben interpretar con cautela los datos sobre cambios de socios comerciales, ya que tanto las pérdidas como las adquisiciones están exageradas. Sin embargo, esta exageración no debería afectar a la esencia de las conclusiones del análisis comparativo.

Todas las cifras presentadas están expresadas en dólares constantes a precios de 2008 a objeto de controlar por la inflación, que en los últimos 20 años ha sido considerable en América Latina, aunque menos problemática que en décadas anteriores. Las cifras de 1990 están deflactadas por el nivel de precios oficial de los Estados Unidos de América, informado por los indicadores del desarrollo mundial del Banco Mundial ${ }^{11}$.

11 Véase [en línea] http://data.worldbank.org/indicator 
Todos los datos se procesaron mediante las rutinas predeterminadas del paquete estadístico estándar IBM SPSS Statistics, versión 19.0.

\section{La calidad del crecimiento de las exportaciones en América Latina}

Para cuantificar el crecimiento de las exportaciones, primero se compara el total de exportaciones de la muestra de países de América Latina en 1990 con el total de 2008 (véase el cuadro 3). Se pueden hacer tres observaciones con respecto al crecimiento real de las exportaciones. En primer lugar, todos los países - excepto la República Bolivariana de Venezuela y el Uruguayal menos duplicaron el valor real de sus exportaciones durante el período en consideración. Con la excepción de Colombia, el Paraguay, el Uruguay y la República Bolivariana de Venezuela, las exportaciones crecieron a una tasa media anual del $7 \%$ o más en todos los países (México y el Perú se destacan al haber alcanzado un crecimiento de dos dígitos). A primera vista, los resultados de las economías latinoamericanas con relación al crecimiento de las exportaciones son alentadores; de hecho, son más que satisfactorios si se comparan con el crecimiento medio anual real del PIB.

No obstante, la diferencia entre el ritmo de crecimiento medio de las exportaciones y el crecimiento medio real del PIB indica que el efecto del primero sobre el segundo no es proporcional. Una segunda conclusión es que no existe una correlación lineal significativa entre la cantidad de tratados firmados y el crecimiento de las exportaciones. En este punto es imperativo realizar un análisis más detallado.

\section{Cambios en los mercados de exportación}

Como ya se mencionó, la calidad del crecimiento depende de la capacidad para exportar una mayor variedad de productos a más mercados (e idealmente, con una distribución más uniforme). Por lo tanto, para desglosar las cifras primero se debe establecer hasta qué punto cambió, si es que cambió, la composición de productos y países. Se comenzará por analizar lo segundo.

Un simple recuento muestra que todos los países del estudio, excepto la República Bolivariana de Venezuela, incrementaron el número de socios comerciales y, por lo tanto, tienen una mayor diversificación geográfica que en 1990 (véase el cuadro 4). Cabe recordar que, a los efectos de este estudio, un país debe recibir exportaciones por más de 500.000 dólares para ser considerado un mercado de destino. El caso venezolano es patológico, ya que como resultado de su excesiva dependencia del petróleo perdió 37 mercados. Otros casos que llaman la atención son el del Brasil (el país más diversificado), el Estado Plurinacional de Bolivia (el menos diversificado, aunque está mejorando), México (el menos exitoso en el acceso a nuevos mercados) y la Argentina (el más exitoso).

\begin{tabular}{|c|c|c|c|c|c|c|}
\hline & $\begin{array}{c}\text { Valor de las } \\
\text { exportaciones } \\
(1990) \\
\text { (Dólares) }\end{array}$ & $\begin{array}{c}\text { Valor de las } \\
\text { exportaciones } \\
(2008) \\
\text { (Dólares) }\end{array}$ & $\begin{array}{l}\text { Crecimiento } \\
\text { absoluto de las } \\
\text { exportaciones } \\
\text { (Dólares) }\end{array}$ & $\begin{array}{l}\text { Crecimiento } \\
\text { relativo de las } \\
\text { exportaciones } \\
\text { (Porcentajes) }\end{array}$ & $\begin{array}{c}\text { Crecimiento } \\
\text { medio anual de } \\
\text { las exportaciones } \\
\text { (Porcentajes) }\end{array}$ & $\begin{array}{c}\text { Crecimiento } \\
\text { medio anual } \\
\text { real del PIB } \\
\text { (Porcentajes) }\end{array}$ \\
\hline Argentina & 18581526 & 60490183 & 41908657 & 226 & 7,2 & 4,0 \\
\hline Bolivia (Estado Plurinacional de) & 1448436 & 5669593 & 4221157 & 291 & 8,4 & 3,7 \\
\hline Brasil & 53407971 & 170528685 & 117120714 & 219 & 7,1 & 2,8 \\
\hline Chile & 14075528 & 62408984 & 48333456 & 343 & 9,2 & 5,2 \\
\hline Colombia & 10840779 & 33490067 & 22649288 & 209 & 6,9 & 3,5 \\
\hline Ecuador & 4342018 & 15493913 & 11151895 & 257 & 7,8 & 3,2 \\
\hline México & 41858114 & 264266121 & 222408006 & 531 & 11,4 & 2,8 \\
\hline Paraguay & 1483131 & 3482506 & 1999375 & 135 & 5,1 & 2,5 \\
\hline Perú & 5074031 & 28703686 & 23629654 & 466 & 10,1 & 4,5 \\
\hline Uruguay & 2674770 & 5281651 & 2606881 & 97 & 4,1 & 2,9 \\
\hline Venezuela (Rep. Bolivariana de) & 25368189 & 46686981 & 21318792 & 84 & 3,7 & 2,9 \\
\hline
\end{tabular}

Fuente: elaboración propia sobre la base de información de las Naciones Unidas, Base de datos estadísticos sobre el comercio de mercaderías (COMTRADE) y Banco Mundial, World Development Indicators.

PIB: producto interno bruto. 
Los productos de América Latina llegaron comparativamente a más mercados en 2008 que en 1990, por lo que, a primera vista, se podría concluir que las exportaciones se encuentran más diversificadas a nivel geográfico, lo que da ciertas esperanzas a los defensores del nexo entre los ALC y la diversificación de las exportaciones. Sin embargo, antes de llegar a esa conclusión es necesario considerar si los principales cinco destinos de esta muestra han registrado grandes cambios (con respecto al valor de las exportaciones). Con este propósito, se calcula la participación de cada socio comercial en el total de exportaciones de cada uno de los países seleccionados de América Latina (véase el cuadro 5).

CUADRO 4

América Latina (países seleccionados): crecimiento
de los destinos de las exportaciones

\begin{tabular}{|c|c|c|c|c|c|c|c|}
\hline & \multirow{2}{*}{$\begin{array}{c}\text { Países de } \\
\text { destino } \\
(1990)\end{array}$} & \multicolumn{2}{|c|}{ Países de destino (2008) } & \multicolumn{2}{|c|}{ Mercados ganados } & \multicolumn{2}{|c|}{ Mercados perdidos } \\
\hline & & $\begin{array}{c}\text { Número } \\
\text { total }\end{array}$ & $\begin{array}{c}\text { Variación } \\
\text { porcentual }\end{array}$ & $\begin{array}{c}\text { Número } \\
\text { total }\end{array}$ & $\begin{array}{c}\text { Variación } \\
\text { porcentual }\end{array}$ & $\begin{array}{c}\text { Número } \\
\text { total }\end{array}$ & $\begin{array}{c}\text { Variación } \\
\text { porcentual }\end{array}$ \\
\hline Argentina & 112 & 160 & 43 & 59 & 53 & 11 & 10 \\
\hline Bolivia (Estado Plurinacional de) & 32 & 52 & 63 & 25 & 78 & 5 & 16 \\
\hline Brasil & 156 & 188 & 21 & 51 & 33 & 19 & 12 \\
\hline Colombia & 82 & 125 & 52 & 52 & 63 & 9 & 11 \\
\hline Ecuador & 59 & 89 & 51 & 39 & 66 & 9 & 15 \\
\hline México & 109 & 147 & 35 & 55 & 50 & 17 & 16 \\
\hline Paraguay & 50 & 77 & 54 & 37 & 74 & 10 & 20 \\
\hline Perú & 84 & 115 & 37 & 39 & 46 & 8 & 10 \\
\hline Uruguay & 74 & 112 & 51 & 49 & 66 & 11 & 15 \\
\hline Venezuela (República Bolivariana de) & 93 & 67 & -28 & 11 & 12 & 37 & 40 \\
\hline
\end{tabular}

Fuente: elaboración propia sobre la base de información de las Naciones Unidas, Base de datos estadísticos sobre el comercio de mercaderías (COMTRADE).

CUADRO 5

América Latina (países seleccionados): principales cinco destinos de las exportaciones, 1990 y 2008

(En porcentajes del total de exportaciones)

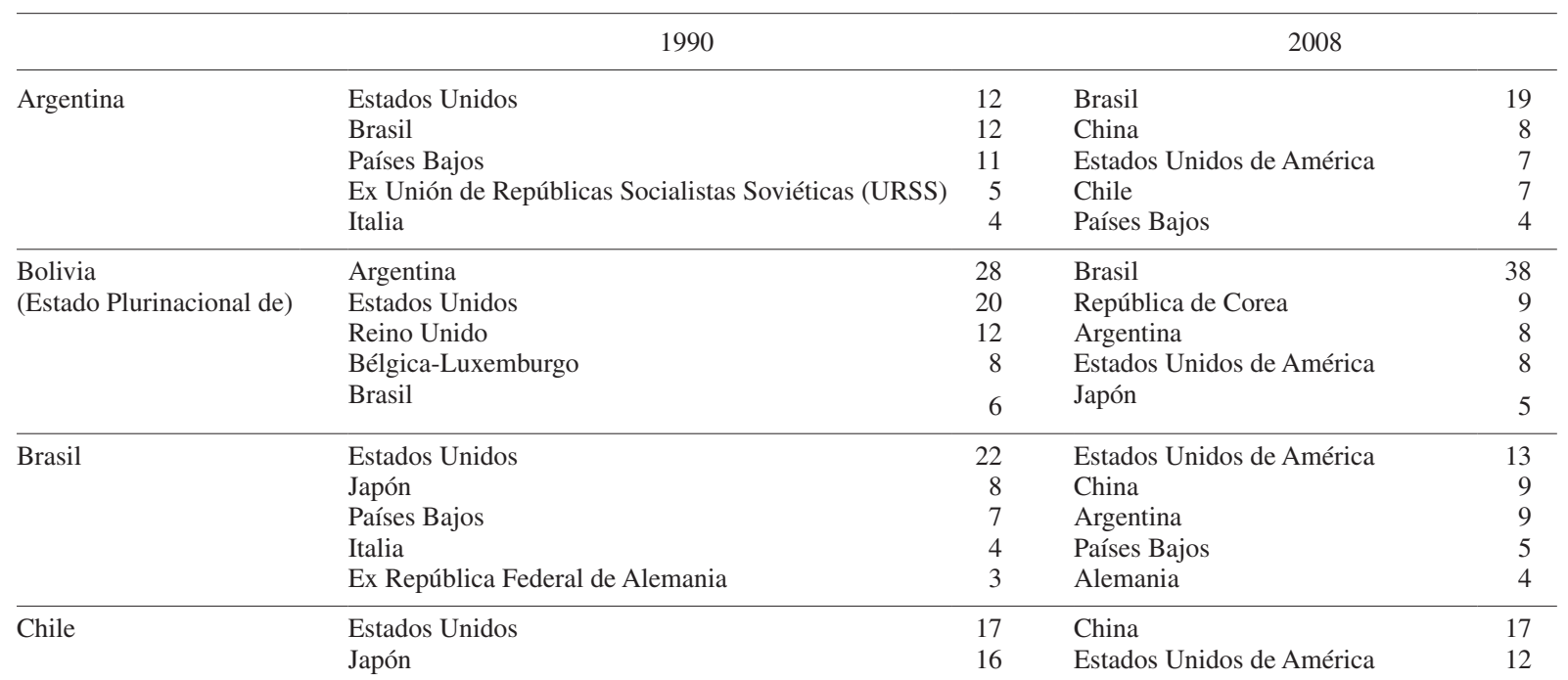

(Continúa en página siguiente) 
(Conclusión)

\begin{tabular}{|c|c|c|c|c|}
\hline & 1990 & & 2008 & \\
\hline Chile & $\begin{array}{l}\text { Ex República Federal de Alemania } \\
\text { Reino Unido de G.B. } \\
\text { Brasil }\end{array}$ & $\begin{array}{l}7 \\
6 \\
6\end{array}$ & $\begin{array}{l}\text { Japón } \\
\text { República de Corea } \\
\text { Países Bajos }\end{array}$ & $\begin{array}{r}10 \\
6 \\
5\end{array}$ \\
\hline Colombia & $\begin{array}{l}\text { Estados Unidos } \\
\text { Ex República Federal de Alemania } \\
\text { Países Bajos } \\
\text { Panamá } \\
\text { Venezuela (República Bolivariana de) }\end{array}$ & $\begin{array}{r}42 \\
5 \\
5 \\
4 \\
4\end{array}$ & $\begin{array}{l}\text { Estados Unidos de América } \\
\text { Venezuela (República Bolivariana de) } \\
\text { Ecuador } \\
\text { Países Bajos } \\
\text { Suiza }\end{array}$ & $\begin{array}{r}38 \\
15 \\
4 \\
3 \\
3\end{array}$ \\
\hline Ecuador & $\begin{array}{l}\text { Estados Unidos } \\
\text { Perú } \\
\text { República de Corea } \\
\text { Antillas Neerlandesas } \\
\text { Panamá }\end{array}$ & $\begin{array}{r}54 \\
6 \\
4 \\
4 \\
4\end{array}$ & $\begin{array}{l}\text { Estados Unidos de América } \\
\text { Perú } \\
\text { Panamá } \\
\text { Chile } \\
\text { Colombia }\end{array}$ & $\begin{array}{r}41 \\
9 \\
7 \\
7 \\
5\end{array}$ \\
\hline México & $\begin{array}{l}\text { Estados Unidos } \\
\text { Japón } \\
\text { España } \\
\text { Francia } \\
\text { Canadá }\end{array}$ & $\begin{array}{r}70 \\
5 \\
5 \\
2 \\
1\end{array}$ & $\begin{array}{l}\text { Estados Unidos de América } \\
\text { Canadá } \\
\text { Alemania } \\
\text { España } \\
\text { Colombia }\end{array}$ & $\begin{array}{r}81 \\
3 \\
2 \\
1 \\
1\end{array}$ \\
\hline Paraguay & $\begin{array}{l}\text { Brasil } \\
\text { Países Bajos } \\
\text { Suiza } \\
\text { Argentina } \\
\text { Estados Unidos }\end{array}$ & $\begin{array}{r}31 \\
16 \\
6 \\
6 \\
4\end{array}$ & $\begin{array}{l}\text { Brasil } \\
\text { Argentina } \\
\text { Uruguay } \\
\text { Chile } \\
\text { Federación de Rusia }\end{array}$ & $\begin{array}{r}17 \\
15 \\
15 \\
9 \\
5\end{array}$ \\
\hline Perú & $\begin{array}{l}\text { Estados Unidos } \\
\text { Japón } \\
\text { Italia } \\
\text { Ex República Federal de Alemania } \\
\text { Reino Unido de G.B. }\end{array}$ & $\begin{array}{r}24 \\
11 \\
7 \\
5 \\
4\end{array}$ & $\begin{array}{l}\text { Estados Unidos de América } \\
\text { China } \\
\text { Suiza } \\
\text { Canadá } \\
\text { Japón }\end{array}$ & $\begin{array}{r}19 \\
13 \\
11 \\
7 \\
6\end{array}$ \\
\hline Uruguay & $\begin{array}{l}\text { Brasil } \\
\text { Estados Unidos } \\
\text { Argentina } \\
\text { Ex República Federal de Alemania } \\
\text { China }\end{array}$ & $\begin{array}{r}27 \\
10 \\
7 \\
5 \\
5\end{array}$ & $\begin{array}{l}\text { Brasil } \\
\text { Zonas francas } \\
\text { Argentina } \\
\text { Estados Unidos de América } \\
\text { Federación de Rusia }\end{array}$ & $\begin{array}{r}18 \\
10 \\
8 \\
6 \\
4\end{array}$ \\
\hline $\begin{array}{l}\text { Venezuela } \\
\text { (Rep. Bolivariana de) }\end{array}$ & $\begin{array}{l}\text { Antillas Neerlandesas } \\
\text { Países Bajos } \\
\text { Canadá }\end{array}$ & $\begin{array}{l}8 \\
4\end{array}$ & $\begin{array}{l}\text { Áreas, n.e.p. } \\
\text { Asociación Latinoamericana de } \\
\text { Integración (ALADI), países n.e.p. } \\
\text { en Base COMTRADE. } \\
\text { Estados Unidos de América } \\
\text { América del Norte y Centroamérica, } \\
\text { países n.e.p. en Base comTRADE } \\
\text { Antillas Neerlandesas }\end{array}$ & $\begin{array}{r}20 \\
19 \\
10 \\
9\end{array}$ \\
\hline
\end{tabular}

Fuente: elaboración propia sobre la base de información de las Naciones Unidas, Base de datos estadísticos sobre el comercio de mercaderías (COMTRADE).

Nota: n.e.p. $=$ datos no especificados en otra parte.

En 2008, Asia y especialmente China se habían convertido en un socio comercial sumamente importante para América Latina, superando a muchos países europeos. También es digna de destacar la creciente importancia del Brasil en la región. Las destinos de exportación de mayor crecimiento fueron China, la República de Corea, el Brasil y, quizás sorprendentemente, los Estados Unidos de
América. La presencia de dicho país en este grupo denota que los mercados tradicionales siguen siendo algunos de los socios comerciales más dinámicos de América Latina, por lo que sería un error concentrarse excesivamente en los nuevos mercados emergentes. Lo más deseable es lograr una mezcla equilibrada de mercados de destino para diversificar los riesgos a nivel geográfico. 
Esto redunda en una segunda conclusión: pese al surgimiento de nuevos mercados, la estructura de las cuotas de mercado de cada país - y por lo tanto, su capacidad de diversificación de los riesgos - no ha cambiado drásticamente. En opinión de los autores de esta investigación, la diversificación no solo supone que la cantidad de socios comerciales sea importante, sino además las cuotas de exportación de cada socio. La concentración de exportaciones no parece haber cambiado mucho, ya que los cinco principales destinos continúan registrando en 2008 cuotas similares a las de 1990 (esto se verificará más adelante). Empeorando las cosas para los defensores del nexo entre los ALC y la diversificación de las exportaciones, ninguno de los socios con mejor comportamiento es nuevo según la definición planteada en este artículo. Los nuevos mercados en las listas de los cinco principales del Uruguay y la República Bolivariana de Venezuela incluyen a una ex república soviética y agrupaciones artificiales debido a la falta de datos más precisos. Por lo tanto, los actuales ALC se limitan a socios comerciales existentes o son incapaces de lograr un acceso considerable a nuevos mercados.

\section{Cambios en los productos exportados}

En esta subsección se evaluará la cantidad de productos exportados, sin olvidar que para identificar a un producto como "nuevo" se aplica un umbral de 50.000 dólares por producto (los productos se definen a nivel de dos dígitos usando la CUCI Rev. 2). Por consiguiente, se cuentan las exportaciones existentes para cada país de la muestra en 1990 y en 2008.

En el cuadro 6 se observa que, con la excepción de México y — curiosamente- de Chile, todos los países comenzaron a exportar nuevos productos durante el período en consideración. Como se observa en la última columna del cuadro 6 ("Productos que ya no se exportan"), el Estado Plurinacional de Bolivia y la República Bolivariana de Venezuela sobresalen por la cantidad de productos que dejaron de exportar entre 1990 y 2008. No obstante, el resultado neto evidencia que las exportaciones de todos los países, con la excepción de la República Bolivariana de Venezuela, presentan una diversificación al menos equivalente en 2008 y en 1990. La situación de este país puede explicarse por su creciente dependencia del petróleo, que actualmente representa el $95 \%$ de sus exportaciones.

$\mathrm{Al}$ desagregar estas cifras (lo que no se ofrece en el presente artículo por falta de espacio), es posible identificar algunas características interesantes. Por ejemplo, el Estado Plurinacional de Bolivia ha dejado de exportar caucho, pero sigue dependiendo mucho de las exportaciones primarias y el petróleo representa una creciente proporción de sus exportaciones. De hecho, en los países de América Latina se verifica una creciente dependencia de los productos básicos. El Perú ha experimentado una importante alza de su cuota de exportaciones bajo el título número 9 (del 1\% al 19\%),

América Latina (países seleccionados): número de exportaciones, definidas a nivel de dos dígitos (cucı Revisión 2)

\begin{tabular}{|c|c|c|c|c|c|c|c|}
\hline & \multirow{2}{*}{$\begin{array}{l}\text { Número de } \\
\text { productos } \\
\text { exportados } \\
\text { (1990) }\end{array}$} & \multicolumn{2}{|c|}{$\begin{array}{l}\text { Número de productos } \\
\text { exportados }(2008)\end{array}$} & \multicolumn{2}{|c|}{$\begin{array}{l}\text { Nuevos productos } \\
\text { exportados }\end{array}$} & \multicolumn{2}{|c|}{$\begin{array}{c}\text { Productos que } \\
\text { ya no se exportan }\end{array}$} \\
\hline & & $\begin{array}{l}\text { Número } \\
\text { total }\end{array}$ & $\begin{array}{c}\text { Variación } \\
\text { porcentual }\end{array}$ & $\begin{array}{l}\text { Número } \\
\text { total }\end{array}$ & $\begin{array}{c}\text { Variación } \\
\text { porcentual }\end{array}$ & $\begin{array}{l}\text { Número } \\
\text { total }\end{array}$ & $\begin{array}{c}\text { Variación } \\
\text { porcentual }\end{array}$ \\
\hline Argentina & 66 & 67 & 2 & 1 & 2 & 0 & 0 \\
\hline Bolivia (Estado Plurinacional de) & 40 & 49 & 23 & 15 & 38 & 6 & 15 \\
\hline Chile & 67 & 67 & 0 & 0 & 0 & 0 & 0 \\
\hline Colombia & 63 & 67 & 6 & 4 & 6 & 0 & 0 \\
\hline Ecuador & 51 & 61 & 20 & 10 & 20 & 0 & 0 \\
\hline México & 68 & 68 & 0 & 0 & 0 & 0 & 0 \\
\hline Paraguay & 50 & 58 & 16 & 9 & 18 & 1 & 2 \\
\hline Perú & 62 & 66 & 7 & 4 & 6 & 0 & 0 \\
\hline Uruguay & 61 & 64 & 5 & 3 & 5 & 0 & 0 \\
\hline Venezuela (República Bolivariana de) & 61 & 59 & -3 & 2 & 3 & 4 & 7 \\
\hline
\end{tabular}

Fuente: elaboración propia sobre la base de información de las Naciones Unidas, Base de datos estadísticos sobre el comercio de mercaderías (COMTRADE).

CUCI: Clasificación Uniforme para el Comercio Internacional. 
el Ecuador registró un descenso de sus exportaciones bajo el título 0 y un importante aumento bajo el título 3 , al tiempo que la cuota de exportaciones del Paraguay se incrementó bajo el título 0 y se redujo bajo el título 2 . Estos cambios, en apariencia estructurales, solo reflejan la sustitución de un producto primario por otro. En el caso del Ecuador, por ejemplo, el sector del petróleo simplemente superó a otros sectores fuertes, como las exportaciones de legumbres y pescado. Los principales productos básicos del Paraguay fueron los cereales y las semillas oleaginosas, y el descenso de la participación relativa del sector textil obedeció a un crecimiento negativo. En el Perú, el cambio en la distribución se atribuye, en gran parte, a un espectacular aumento de las exportaciones de oro. Más allá de cuán prometedor pueda ser este desempeño, se trata de un sector tradicional de la economía peruana que se remonta a los tiempos precoloniales. En otras palabras, pese a la impresión de que ha ocurrido un cambio estructural, la composición de las exportaciones de la región sigue estando limitada a productos básicos.

Una posible excepción es la que presenta México, un país cuyo impresionante crecimiento en los sectores de maquinaria y equipos de transporte (del 27\% al 53\%) y de manufacturas (del $4 \%$ al 10\%) indica que exportó productos de mayor valor agregado. Sin embargo, es más probable que este incremento se atribuya al sector de la maquila (véase, por ejemplo, Kopinak, 1996). La fuerte presencia de los Estados Unidos de América en la economía mexicana supone que probablemente existan pocos efectos secundarios. Los defensores del nexo entre los ALC y la diversificación de las exportaciones pueden, sin embargo, afirmar que este efecto positivo, aunque limitado, se debe principalmente a la firma del Tratado de Libre Comercio de América del Norte (TLCAN) por parte de México. Si bien esto puede ser cierto, los datos permiten ver que con este tratado no se ha concretado la exportación de nuevos productos y que sus efectos en la diversificación de las exportaciones y el cambio estructural son, como mucho, moderados.

Ni siquiera Chile, el país que más exporta en América Latina, muestra un desempeño satisfactorio. Según los datos, sus principales exportaciones son los metales no ferrosos (principalmente el cobre), las menas (también el cobre) y las legumbres y frutas, lo que demuestra la gran dependencia de los productos primarios de sus exportaciones.

En el cuadro 7 se aprecia claramente esta tendencia mediante la presentación de las tres principales exportaciones en términos de valor para la muestra de países seleccionados.
En virtud de estos datos, se puede concluir que se han verificado pocos cambios en la estructura de exportaciones de la región. A juzgar por las cifras registradas por los tres principales productos de exportación en cada país, la distribución de las exportaciones en 2008 es muy similar a la de 1990. En efecto, las economías latinoamericanas continúan estando muy concentradas en los productos primarios y dependen mucho de ellos.

En resumen, los datos ofrecidos en esta investigación revelan que no se han producido grandes cambios en la estructura de producción de estos sectores exportadores, ni se ha constatado el incremento deseado en productos con mayor valor agregado. Ni siquiera las dos excepciones (la Argentina y México) han podido crear nuevos productos de mayor valor agregado. En consecuencia, no es esperable ver un crecimiento significativo en el margen extensivo (véase la siguiente subsección).

\section{Crecimiento en los márgenes extensivo e intensivo}

A continuación se abordará la calidad del crecimiento de las exportaciones de América Latina en el período 1990-2008. El nivel de diversificación puede evaluarse mediante la cuantificación del crecimiento en los márgenes extensivo e intensivo y el cálculo de los índices de concentración pertinentes. Se utiliza la definición de márgenes extensivo e intensivo de Brenton y Newfarmer (2009, pág. 112), según la cual el crecimiento de las exportaciones puede ocurrir en relación con los mercados o productos de un país, cada uno de los cuales puede ser nuevo o existente, con lo que se tienen cuatro combinaciones posibles.

La expansión de las exportaciones de un producto existente hacia un mercado existente contribuye al crecimiento del margen intensivo. El aumento de las exportaciones de un nuevo producto hacia un nuevo mercado puede clasificarse como crecimiento de las exportaciones en el margen extensivo (que se denominará tipo II). Las dos combinaciones restantes contienen un elemento nuevo y otro existente. El crecimiento de las exportaciones tipo I $a$ en el margen extensivo involucra la exportación de un nuevo producto a un mercado existente. Por último, se hará referencia al aumento de las exportaciones de un producto básico existente hacia un nuevo mercado como crecimiento de las exportaciones tipo $\mathrm{I} b$ en el margen extensivo (véase el cuadro 8).

Los datos del cuadro 8 confirman lo que se sospechaba, pues indican que, en general, el crecimiento de las exportaciones en América Latina involucra la 
CUADRO 7

América Latina (países seleccionados): tres principales exportaciones definidas a nivel de dos dígitos (CUCl Rev. 2) en términos de valor, 1990 y 2008 (En dólares constantes a precios de 2008 y porcentajes del total de exportaciones)

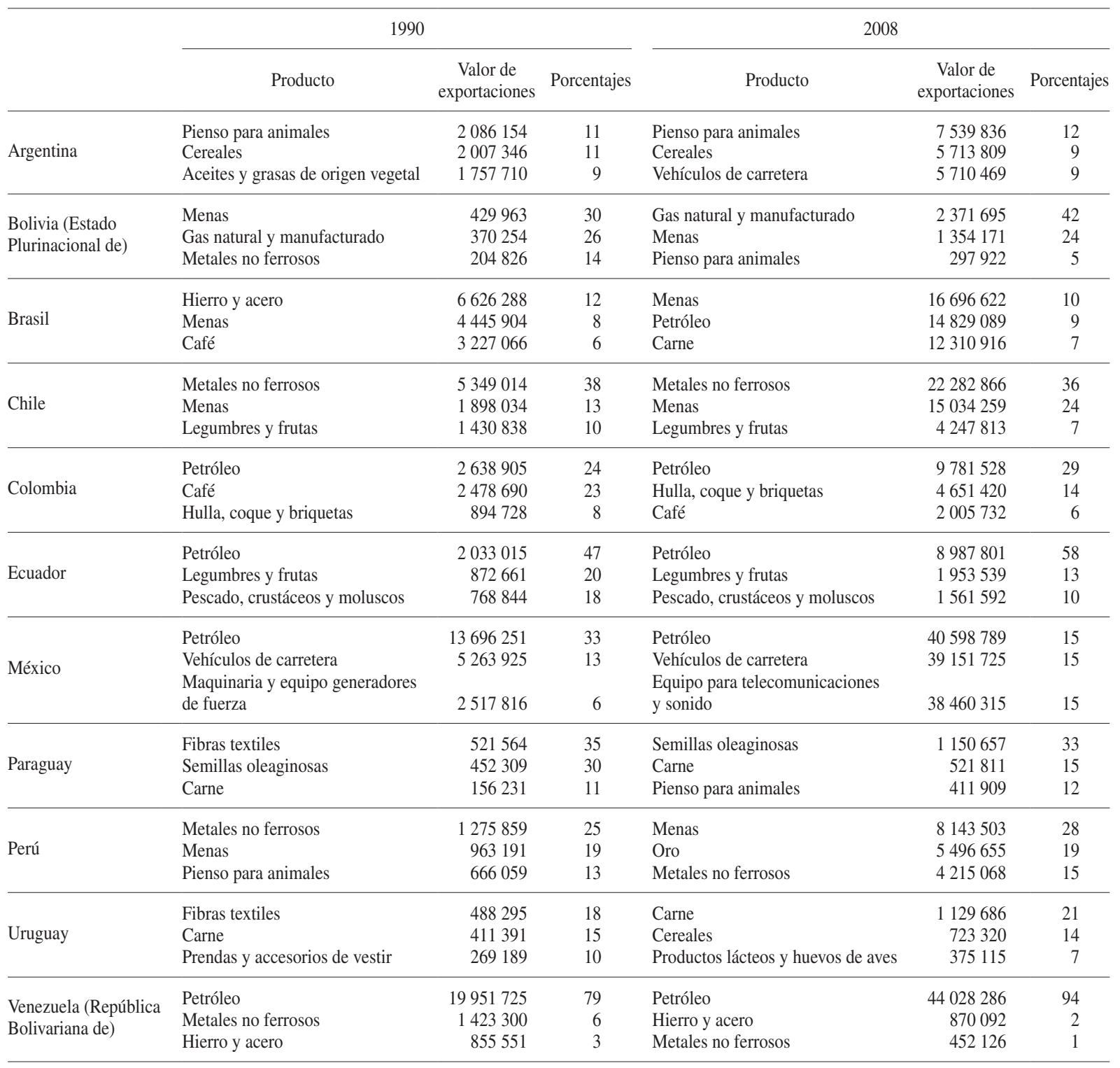

Fuente: elaboración propia sobre la base de información de las Naciones Unidas, Base de datos estadísticos sobre el comercio de mercaderías (COMTRADE).

CUCI: Clasificación Uniforme para el Comercio Internacional. 
América Latina (países seleccionados): crecimiento de las exportaciones en los márgenes extensivo e intensivo

(En dólares constantes a precios de 2008 y porcentajes)

\begin{tabular}{|c|c|c|c|c|c|c|c|c|c|}
\hline & \multirow{2}{*}{$\begin{array}{c}\text { Crecimiento total } \\
\text { de las exportaciones } \\
\text { (Dólares) }\end{array}$} & \multicolumn{2}{|c|}{ Margen intensivo } & \multicolumn{2}{|c|}{ Margen extensivo I $a$} & \multicolumn{2}{|c|}{ Margen extensivo $\mathrm{I} b$} & \multicolumn{2}{|c|}{ Margen extensivo II } \\
\hline & & (Dólares) & (Porcentajes) & (Dólares) & (Porcentajes) & (Dólares) & (Porcentajes) & (Dólares) & (Porcentajes) \\
\hline Argentina & 41908657 & 37921985 & 90,5 & 767685 & 1,8 & 3218058 & 7,7 & 930 & 0,0 \\
\hline $\begin{array}{l}\text { Bolivia (Estado } \\
\text { Plurinacional de) }\end{array}$ & 4221157 & 3665666 & 86,8 & 167837 & 4,0 & 385234 & 9,1 & 2420 & 0,1 \\
\hline Brasil & 117120714 & 103406173 & 88,3 & 381132 & 0,3 & 13333410 & 11,4 & $\ldots$ & 0,0 \\
\hline Chile & 48333456 & 46374130 & 95,9 & $\ldots$ & 0,0 & 1959326 & 4,1 & $\ldots$ & 0,0 \\
\hline Colombia & 22649288 & 20325116 & 89,7 & 1347289 & 5,9 & 976883 & 4,3 & $\ldots$ & 0,0 \\
\hline Ecuador & 11151895 & 9762534 & 87,5 & 120609 & 1,1 & 1228834 & 11,0 & 39918 & 0,4 \\
\hline México & 222408006 & 219870841 & 98,9 & $\ldots$ & 0,0 & 2537166 & 1,1 & $\ldots$ & 0,0 \\
\hline Paraguay & 1999375 & 1502079 & 75,1 & 10290 & 0,5 & 486611 & 24,3 & 395 & 0,0 \\
\hline Perú & 23629593 & 22920015 & 97,0 & 7876 & 3,0 & 701599 & 0,0 & 350 & 0,0 \\
\hline Uruguay & 2606881 & 1461283 & 56,1 & 26565 & 1,0 & 1119002 & 42,9 & 31 & 0,0 \\
\hline $\begin{array}{l}\text { Venezuela (República } \\
\text { Bolivariana de) }\end{array}$ & 21318792 & 6133959 & 28,8 & 12198 & 0,1 & 15172632 & 71,2 & 3 & 0,0 \\
\hline
\end{tabular}

Fuente: elaboración propia sobre la base de información de Naciones Unidas, Base de datos estadísticos sobre el comercio de mercaderías (COMTRADE).

expansión de productos existentes hacia mercados existentes (margen intensivo). Incluso en el caso de Chile, el país que más acuerdos comerciales ha firmado en la región, el margen intensivo representa el 95,9\% del crecimiento total de las exportaciones. En México, la cifra es aún más extrema, ya que el $98,9 \%$ del crecimiento total de sus exportaciones se ubica en el margen intensivo. La ausencia casi total de crecimiento de tipo II en el margen extensivo refleja el fracaso generalizado de la actual estrategia de posicionamiento económico internacional de América Latina para crear nuevas oportunidades. Cuando se analiza la calidad del crecimiento desglosado en conformidad con los 10 títulos de la sección de un dígito de la CUCI Rev. 2, se puede confirmar que las economías latinoamericanas casi no han logrado ningún crecimiento extensivo en los sectores de alta tecnología o mayor valor agregado.

Empero, hay un atisbo de esperanza para los defensores del nexo entre los ALC y la diversificación de las exportaciones. Las economías de la región han obtenido resultados relativamente mejores en el logro de un crecimiento extensivo respecto de nuevos mercados. En lo que sigue se analizará hasta qué punto los ALC (y los acuerdos comerciales en general) son responsables de la creación de nuevos mercados, examinando cómo los cambios en las cuotas de los productos y mercados de exportación han contribuido a la diversificación o concentración relativa de las exportaciones.

\section{6. ¿Diversificación o concentración de las exportaciones?}

La diversificación de las exportaciones se puede medir de muchas maneras. En este estudio se ha optado por utilizar cuatro índices de concentración comunes, identificados por Samen (2010): el Índice de Herfindahl, el Îndice de Hirschman, el Índice Ojiva y el Índice de Entropía. No obstante, más allá de la práctica habitual de calcular estos índices solo para productos, también se calcularán para países. De este modo, para cada país se tendrán dos valores respecto de cada índice de concentración: uno en relación con los productos y otro en relación con los socios comerciales.

El Índice de Herfindahl para el país $j$ se define de la siguiente manera:

$$
H I 1_{j}=\sum_{i=1}^{N}\left(\frac{x_{i}}{X_{j}}\right)^{2}
$$

donde $x_{i}$ se define como el total de exportaciones del producto $i$ o como el total de exportaciones al país $i$, y $X_{j}$ se define como el total de exportaciones del país $j . N$ es el número total de productos (o países). La definición de estos símbolos se mantendrá en todo el presente artículo.

El Índice de Hirschman para el país $j$ se define de la siguiente manera: 


$$
H I 2_{j}=\sqrt{\sum_{i=1}^{N}\left(\frac{x_{i}}{X_{j}}\right)^{2}}
$$

Básicamente, el Índice de Hirschman es igual a la raíz del Índice de Herfindahl. En ambos casos se compara la concentración efectiva con una composición de productos (o mercados de exportación) distribuida de manera uniforme, y un índice más alto indica una mayor concentración de exportaciones. En el caso de la concentración absoluta, el índice sería igual a uno; en el caso más diversificado sería cercano a cero.

El Índice Ojiva para el país $j$ se define de la siguiente manera:

$$
0 J V_{j}=N \sum_{i=1}^{N}\left(\frac{x_{i}}{X_{j}}-1 / N\right)^{2}
$$

Este índice mide la desviación a partir de una distribución pareja de las cuotas de exportación (en términos de productos y países). $1 / \mathrm{N}$ se considera la cuota ideal de un producto (o socio comercial) en el total de exportaciones. Cuando el valor se aproxima a cero significa que el sector exportador está muy diversificado. Un índice cercano a uno significa que está muy concentrado.

Finalmente, el Índice de Entropía para el país $j$ se define de la siguiente manera:

$$
E N T_{j}=\sum_{i=1}^{N}\left(\frac{x_{i}}{X_{j}} x \log _{2}\left(\frac{X_{j}}{x_{i}}\right)\right)
$$

A diferencia de las otras medidas, el máximo se alcanza cuando todos los productos (o países) presentan una distribución uniforme. Por lo tanto, los valores más bajos indican una mayor concentración de exportaciones.

Los resultados de estos cuatro índices se presentan en el cuadro 9. Como dichos resultados son concordantes, el análisis se centrará en el Índice de Herfindahl.

De los índices es posible extraer algunas conclusiones interesantes. En primer lugar, tiende a existir una

CUADRO 9

América Latina (países seleccionados): índices de concentración

\begin{tabular}{|c|c|c|c|c|c|}
\hline & \multirow{2}{*}{ Índice } & \multicolumn{2}{|c|}{ Productos } & \multicolumn{2}{|c|}{ Socios comerciales } \\
\hline & & 1990 & 2008 & 1990 & 2008 \\
\hline \multirow{4}{*}{ Argentina } & HI1 & 0,060 & 0,058 & 0,055 & 0,064 \\
\hline & HI2 & 0,244 & 0,242 & 0,235 & 0,254 \\
\hline & OJV & 2,972 & 2,932 & 5,274 & 7,478 \\
\hline & ENT & 4,632 & 4,736 & 5,001 & 5,045 \\
\hline \multirow{4}{*}{ Bolivia (Estado Plurinacional de) } & HI1 & 0,180 & 0,242 & 0,151 & 0,176 \\
\hline & HI2 & 0,425 & 0,492 & 0,388 & 0,419 \\
\hline & OJV & 6,765 & 11,140 & 9,926 & 8,097 \\
\hline & ENT & 3,212 & 2,925 & 3,337 & 3,471 \\
\hline \multirow{4}{*}{ Brasil } & HI1 & 0,046 & 0,044 & 0,073 & 0,047 \\
\hline & HI2 & 0,215 & 0,211 & 0,270 & 0,217 \\
\hline & OJV & 2,076 & 1,991 & 8,768 & 7,076 \\
\hline & ENT & 4,970 & 5,012 & 5,046 & 5,372 \\
\hline \multirow{4}{*}{ Chile } & HI1 & 0,184 & 0,197 & 0,079 & 0,072 \\
\hline & HI2 & 0,429 & 0,443 & 0,280 & 0,268 \\
\hline & OJV & 11,333 & 12,178 & 6,290 & 6,464 \\
\hline & ENT & 3,477 & 3,403 & 4,458 & 4,559 \\
\hline \multirow{4}{*}{ Colombia } & HI1 & 0,133 & 0,119 & 0,192 & 0,175 \\
\hline & HI2 & 0,364 & 0,345 & 0,438 & 0,418 \\
\hline & OJV & 7,434 & 6,970 & 12,828 & 14,741 \\
\hline & ENT & 3,758 & 4,200 & 3,873 & 3,913 \\
\hline
\end{tabular}
comúnmente utilizados, calculados para socios comerciales y productos definidos a nivel de dos dígitos (cucı Revisión 2) 


\begin{tabular}{|c|c|c|c|c|c|}
\hline & \multirow{2}{*}{ Índice } & \multicolumn{2}{|c|}{ Productos } & \multicolumn{2}{|c|}{ Socios comerciales } \\
\hline & & 1990 & 2008 & 1990 & 2008 \\
\hline Ecuador & $\begin{array}{l}\text { HI1 } \\
\text { HI2 } \\
\text { OJV } \\
\text { ENT }\end{array}$ & $\begin{array}{r}0,300 \\
0,548 \\
14,628 \\
2,243\end{array}$ & $\begin{array}{r}0,365 \\
0,604 \\
21,384 \\
2,498\end{array}$ & $\begin{array}{r}0,303 \\
0,550 \\
14,201 \\
3,111\end{array}$ & $\begin{array}{r}0,193 \\
0,440 \\
11,981 \\
3,581\end{array}$ \\
\hline México & $\begin{array}{l}\text { HI1 } \\
\text { HI2 } \\
\text { OJV } \\
\text { ENT }\end{array}$ & $\begin{array}{l}0,136 \\
0,369 \\
8,244 \\
4,130\end{array}$ & $\begin{array}{l}0,086 \\
0,294 \\
4,870 \\
4,297\end{array}$ & $\begin{array}{r}0,496 \\
0,704 \\
38,355 \\
2,317\end{array}$ & $\begin{array}{r}0,659 \\
0,812 \\
66,268 \\
1,654\end{array}$ \\
\hline Paraguay & $\begin{array}{l}\text { HI1 } \\
\text { HI2 } \\
\text { OJV } \\
\text { ENT }\end{array}$ & $\begin{array}{r}0,233 \\
0,482 \\
10,856 \\
2,817\end{array}$ & $\begin{array}{l}0,172 \\
0,414 \\
9,015 \\
3,276\end{array}$ & $\begin{array}{l}0,141 \\
0,375 \\
8,112 \\
3,762\end{array}$ & $\begin{array}{l}0,093 \\
0,305 \\
5,780 \\
4,288\end{array}$ \\
\hline Perú & $\begin{array}{l}\text { HI1 } \\
\text { HI2 } \\
\text { OJV } \\
\text { ENT }\end{array}$ & $\begin{array}{l}0,136 \\
0,369 \\
7,417 \\
3,538\end{array}$ & $\begin{array}{l}0,154 \\
0,392 \\
9,179 \\
3,422\end{array}$ & $\begin{array}{l}0,084 \\
0,290 \\
6,317 \\
4,513\end{array}$ & $\begin{array}{l}0,082 \\
0,287 \\
6,470 \\
4,341\end{array}$ \\
\hline Uruguay & $\begin{array}{l}\text { HI1 } \\
\text { HI2 } \\
\text { OJV } \\
\text { ENT }\end{array}$ & $\begin{array}{l}0,093 \\
0,304 \\
4,709 \\
4,144\end{array}$ & $\begin{array}{l}0,086 \\
0,294 \\
4,538 \\
4,393\end{array}$ & $\begin{array}{l}0,104 \\
0,323 \\
7,306 \\
4,308\end{array}$ & $\begin{array}{l}0,064 \\
0,254 \\
5,320 \\
4,900\end{array}$ \\
\hline Venezuela (República Bolivariana de) & $\begin{array}{l}\text { HI1 } \\
\text { HI2 } \\
\text { OJV } \\
\text { ENT }\end{array}$ & $\begin{array}{r}0,624 \\
0,790 \\
37,169 \\
1,631\end{array}$ & $\begin{array}{r}0,890 \\
0,943 \\
51,654 \\
0,523\end{array}$ & $\begin{array}{r}0,292 \\
0,541 \\
18,323 \\
3,204\end{array}$ & $\begin{array}{l}0,164 \\
0,405 \\
8,677 \\
3,102\end{array}$ \\
\hline
\end{tabular}

Fuente: elaboración propia sobre la base de información de las Naciones Unidas, Base de datos estadísticos sobre el comercio de mercaderías (COMTRADE).

Nota: HI1 = Índice de Herfindahl; HI2 = Índice de Hirschman; OJV = Índice Ojiva; ENT = Índice de Entropía.

CUCI: Clasificación Uniforme para el Comercio Internacional.

correlación entre los índices para productos y socios comerciales, con las únicas excepciones de México y la República Bolivariana de Venezuela, debido a los motivos ya mencionados. En segundo término, solo cuatro países lograron diversificar tanto sus mercados como sus exportaciones (el Brasil, Colombia, el Paraguay y el Uruguay), aunque en general estos cambios solo fueron mínimos. La tercera conclusión es que, por pequeña que fuera, se logró una mayor diversificación en relación con los mercados de destino que con los productos.

Antes de sacar rápidas conclusiones, se debe reconocer la sensibilidad (con la excepción del Índice Ojiva) de estos índices respecto del número de productos y socios comerciales. El índice favorece a los países con un $N$ bajo (ceteris paribus). Por lo tanto, es común comparar estos índices considerando un $N$ fijo. Los resultados para los 10 principales productos y mercados exportadores se exponen en el cuadro 10.
Al controlar por el número de productos exportados y socios comerciales, se encuentra que los únicos dos países que han logrado una diversificación en ambas dimensiones son el Brasil y el Paraguay. La estructura de las exportaciones de Colombia y el Uruguay es relativamente pequeña si se compara con el resto de América Latina, ya que sus economías están cada vez más concentradas en productos básicos. El hecho de que obtengan mejores puntajes en el Índice de Herfindahl respecto del Estado Plurinacional de Bolivia, que tiene una cantidad incluso menor de productos exportados, no es una contradicción: los tres principales exportadores de este último país representan una cuota superior que los de Colombia y el Uruguay.

Otra diferencia en los valores registrados por los dos índices es que, según el Índice de Herfindahl, Chile es el país más diversificado en lo que respecta a socios comerciales, mientras que el Índice Ojiva lo coloca en 


\begin{tabular}{lccrr}
\hline & \multicolumn{2}{c}{ Productos } & \multicolumn{2}{c}{ Socios comerciales } \\
\cline { 2 - 4 } & 1990 & 2008 & 1990 & 2008 \\
\hline Argentina & 0,113 & 0,125 & 0,138 & 0,171 \\
Bolivia (Estado Plurinacional de) & 0,230 & 0,290 & 0,181 & 0,233 \\
Brasil & 0,124 & 0,117 & 0,194 & 0,147 \\
Chile & 0,245 & 0,278 & 0,342 & 0,142 \\
Colombia & 0,191 & 0,230 & 0,431 & 0,322 \\
Ecuador & 0,318 & 0,432 & 0,643 & 0,278 \\
México & 0,261 & 0,152 & 0,179 & 0,783 \\
Paraguay & 0,266 & 0,211 & 0,193 \\
Perú & 0,172 & 0,189 & 0,147 \\
Uruguay & 0,146 & 0,163 & 0,427 & 0,149 \\
Venezuela (República Bolivariana de) & 0,710 & 0,910 & & 0,187 \\
\hline
\end{tabular}

Fuente: elaboración propia sobre la base de información de las Naciones Unidas, Base de datos estadísticos sobre el comercio de mercaderías (COMTRADE).

CUCI: Clasificación Uniforme para el Comercio Internacional.

el tercer lugar, detrás del Paraguay y el Uruguay. La diferencia es que este Índice de Herfindahl particular excluye países, mientras que el Índice Ojiva no. Algo en común entre ambos índices es que Chile ha logrado mejores resultados en la diversificación de sus socios comerciales que en la de los productos que exporta.

En suma, estos índices de concentración no produjeron ningún resultado muy sorprendente. Los limitados cambios estructurales que revelaron muestran una mayor diversificación en materia de socios comerciales que de productos. Esto viene a respaldar la afirmación de este estudio en cuanto a que la estructura productiva del sector exportador en los países de América Latina no ha cambiado de manera significativa. La ausencia de un efecto no supone necesariamente que los ALC (y los acuerdos comerciales en general) no sean eficaces y quizás los resultados hubieran sido peores si no se hubiera firmado ningún acuerdo de este tipo. No obstante, esto es muy improbable, cuestión que se analizará en la subsección siguiente.

\section{ALC y diversificación}

La importancia de los ALC no es solo nominal: como se ilustra en el cuadro 11, las exportaciones cubiertas por un acuerdo de comercio preferencial o un ALC han aumentado desde 1990 en todos los países, menos en el Uruguay.

La creciente cobertura de los acuerdos comerciales no es para nada sorprendente si se tiene en cuenta que la mayoría de ellos se firmaron después de 1990. Sin embargo, su efecto ha sido asombroso en los casos de México y Chile, donde un $94 \%$ y un $81 \%$, respectivamente, del comercio con otros países se cubre con este tipo de acuerdos. En el otro extremo, en Colombia, el Ecuador y la República Bolivariana de Venezuela los ALC cubren menos del $10 \%$ del total de sus exportaciones.

En el cuadro 12 se puede verificar si estos ALC crearon nuevos mercados o simplemente confirmaron los lazos que ya existían.

Los datos dejan ver que el comercio con futuros socios comerciales ya era relativamente importante en 1990. Con excepción de la República Bolivariana de Venezuela, la participación de futuros socios comerciales en las exportaciones totales aumentó significativamente para todos los países. De hecho, el crecimiento anual de las exportaciones a futuros socios comerciales es, nuevamente salvo la República Bolivariana de Venezuela, superior al crecimiento anual de las exportaciones a "todos" los países (véase el cuadro 3). Pero dada la importancia que estos destinos ya constituían para las economías en cuestión, difícilmente se puede afirmar que los acuerdos comerciales "abrieron" nuevos mercados.

En términos de acceso a nuevos mercados, los datos obtenidos indican que solo seis países comenzaron a exportar a nuevos países (según el umbral) en virtud de un acuerdo comercial. Sin considerar los países de Europa oriental establecidos tras la disolución de la Unión Soviética y otros cambios artificiales (como la separación de los datos de Bélgica y Luxemburgo en 
CUADRO 11

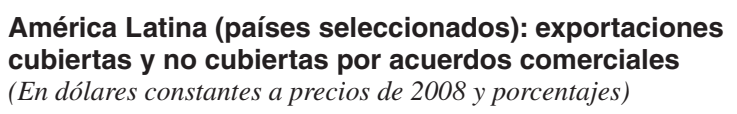

cubiertas y no cubiertas por acuerdos comerciales

(En dólares constantes a precios de 2008 y porcentajes)

\begin{tabular}{|c|c|c|c|c|c|c|c|c|}
\hline & \multicolumn{4}{|c|}{$\begin{array}{c}\text { Total de exportaciones } \\
1990\end{array}$} & \multicolumn{4}{|c|}{$\begin{array}{l}\text { Total de exportaciones } \\
2008\end{array}$} \\
\hline & \multicolumn{2}{|c|}{ Sin acuerdo } & \multicolumn{2}{|c|}{ Con acuerdo } & \multicolumn{2}{|c|}{ Sin acuerdo } & \multicolumn{2}{|c|}{ Con acuerdo } \\
\hline & Dólares & Porcentajes & Dólares & Porcentajes & Dólares & Porcentajes & Dólares & Porcentajes \\
\hline Argentina & 18582 & 100 & 0 & 0 & 36717272 & 61 & 23772911 & 39 \\
\hline $\begin{array}{l}\text { Bolivia (Estado } \\
\quad \text { Plurinacional de) }\end{array}$ & 1448436 & 100 & 0 & 0 & 3032614 & 53 & 2636979 & 47 \\
\hline Brasil & 53407971 & 100 & 0 & 0 & 137078944 & 80 & 33449741 & 20 \\
\hline Chile & 14075528 & 100 & 0 & 0 & 11772471 & 19 & 50636513 & 81 \\
\hline Colombia & 10294937 & 95 & 545841 & 5 & 30498885 & 91 & 2991182 & 9 \\
\hline Ecuador & 4342018 & 100 & 0 & 0 & 14334362 & 93 & 1159551 & 7 \\
\hline México & 41229536 & 98 & 628579 & 2 & 16331152 & 6 & 247934969 & 94 \\
\hline Paraguay & 1483131 & 100 & 0 & 0 & 2294703 & 66 & 1187803 & 34 \\
\hline Perú & 4930197 & 98 & 91303 & 2 & 18980869 & 66 & 9722816 & 34 \\
\hline Uruguay & 1944685 & 73 & 730086 & 27 & 4231930 & 80 & 1049721 & 20 \\
\hline $\begin{array}{l}\text { Venezuela (República } \\
\text { Bolivariana de) }\end{array}$ & 24680937 & 97 & 687252 & 3 & 44806718 & 96 & 1880264 & 4 \\
\hline
\end{tabular}

Fuente: elaboración propia sobre la base de información de las Naciones Unidas, Base de datos estadísticos sobre el comercio de mercaderías (COMTRADE).

CUADRO 12

América Latina (países seleccionados): exportaciones a socios comerciales antes y después de la firma de acuerdos comerciales, 1990 y 2008

(En dólares constantes a precios de 2008 y porcentajes del total de exportaciones)

\begin{tabular}{|c|c|c|c|c|c|}
\hline & \multicolumn{2}{|c|}{$\begin{array}{l}\text { Exportaciones a futuros } \\
\text { socios de ALC (1990) }\end{array}$} & \multicolumn{2}{|c|}{$\begin{array}{l}\text { Exportaciones a socios } \\
\text { de ALC (2008) }\end{array}$} & \multirow{2}{*}{$\begin{array}{c}\text { Crecimiento } \\
\text { medio anual } \\
\text { (en porcentajes) }\end{array}$} \\
\hline & Dólares & Porcentajes & Dólares & Porcentajes & \\
\hline Argentina & 4870976 & 26,20 & 23772911 & 39,30 & 9,8 \\
\hline Bolivia (Estado Plurinacional de) & 495557 & 34,20 & 2636979 & 46,50 & 10,3 \\
\hline Brasil & 5586579 & 10,50 & 33449741 & 19,60 & 11,1 \\
\hline Chile & 9758851 & 69,30 & 50636513 & 81,10 & 10,2 \\
\hline Colombia & 607489 & 5,60 & 2991182 & 8,90 & 9,8 \\
\hline Ecuador & 178728 & 4,10 & 1159551 & 7,50 & 11,6 \\
\hline México & 37302311 & 89,10 & 247934969 & 93,80 & 11,8 \\
\hline Paraguay & 161372 & 10,90 & 1187803 & 34,10 & 12,5 \\
\hline Perú & 1513771 & 30,10 & 9722816 & 33,90 & 11,6 \\
\hline Uruguay & 344525 & 12,90 & 1049721 & 19,90 & 6,8 \\
\hline Venezuela (República Bolivariana de) & 1943532 & 7,70 & 1880264 & 4,00 & $-0,2$ \\
\hline
\end{tabular}

Fuente: elaboración propia sobre la base de información de las Naciones Unidas, Base de datos estadísticos sobre el comercio de mercaderías (COMTRADE).

la COMTRADE), Chile obtuvo acceso a los mercados de Bulgaria, Islandia y Malta; Colombia a los de Antigua y Barbuda, Belice, Guyana y Saint Kitts y Nevis; el Ecuador a los del Paraguay y el Uruguay (que no alcanzó el umbral en 1990); México a los de Bulgaria,
Islandia y Rumania; el Paraguay al del Ecuador (que no alcanzó el umbral en 1990); y la República Bolivariana de Venezuela al de Belice. Esta lista no es gran cosa: el acceso obtenido representa menos del $1 \%$ del total de exportaciones de estos países en 2008 (por lo tanto, los 
resultados son insignificantes desde el punto de vista económico). Bulgaria y Rumania eran nuevos actores en la economía de mercado, por lo que no está claro que un ALC con la Unión Europea fuera necesario para obtener acceso a sus mercados. El Ecuador, el Paraguay y el Uruguay son socios comerciales naturales y el comercio entre ellos probablemente se habría expandido incluso sin la firma de un acuerdo comercial.

Todo esto demuestra que, en general, los ALC (y los acuerdos comerciales en general) han sido más bien ineficaces a la hora de promover el acceso a los mercados, sobre todo a nuevos mercados. Por supuesto que una interpretación optimista sería que, dada esta diferencia en las tasas de crecimiento, aún hay mercados dinámicos disponibles con los que los países de América Latina podrían firmar ALC para mejorar aún más su desempeño. Si bien esto es posible, en el caso de Chile, por ejemplo, quedan muy pocos países con los que no haya firmado un acuerdo. Además, el crecimiento más notorio se ha registrado en las exportaciones a los Estados Unidos de América y China, países con los que ya existen fuertes vínculos económicos. Desde el punto de vista de la diversificación geográfica, la firma de un ALC con cualquiera de estos dos países no tendría mucho sentido.

Otra hipótesis es que si se firmaran ALC con nuevos socios comerciales, el crecimiento de las exportaciones tipo I $b$ en el margen intensivo ocurriría de manera natural, y que por lo tanto no se estaría midiendo realmente el verdadero potencial de los ALC. En teoría esto es cierto, pero la lista de socios comerciales existentes deja poco lugar para una mayor expansión. Es cuestionable que los resultados compensarían los esfuerzos diplomáticos que implica la negociación de acuerdos con los países que restan, pequeños la mayoría de ellos. Lo cierto es que, dados los vínculos económicos existentes y creados endógenamente, el argumento más fuerte en favor de la firma de un ALC no es obtener acceso a nuevos mercados, sino diversificar la estructura de exportaciones de una economía. Es evidente que los países desean alcanzar un crecimiento en el margen intensivo, pero esta es una ganancia a corto plazo. La ganancia a largo plazo se logra mediante la diversificación y los ALC no resultan eficaces para este fin.

En el cuadro 13 se evidencia que, con excepción de los casos del Brasil y la República Bolivariana de Venezuela, los acuerdos comerciales no han desempeñado un papel decisivo en el fomento de la exportación de nuevos productos. De hecho, la forma "más pura" de diversificación (nuevos países y nuevos productos) no se ha logrado con ningún acuerdo comercial.

Aquí finaliza esta evaluación preliminar de la relación entre los acuerdos comerciales en general y los ALC en particular, y la diversificación de las exportaciones en términos tanto de socios comerciales como de productos. El análisis de los datos ha confirmado la principal hipótesis de este estudio: los ALC son una herramienta útil, y quizás necesaria, para la estrategia de por tipo de crecimiento y existencia de un acuerdo comercial (En miles de dólares constantes a precios de 2008 y porcentajes)

\begin{tabular}{|c|c|c|c|c|c|c|c|c|}
\hline & \multicolumn{4}{|c|}{ Margen extensivo I $a$} & \multicolumn{4}{|c|}{ Margen extensivo II } \\
\hline & \multicolumn{2}{|c|}{ Sin acuerdo } & \multicolumn{2}{|c|}{ Con acuerdo } & \multicolumn{2}{|c|}{ Sin acuerdo } & \multicolumn{2}{|c|}{ Con acuerdo } \\
\hline & Dólares & Porcentajes & Dólares & Porcentajes & Dólares & Porcentajes & Dólares & Porcentajes \\
\hline Argentina & 767560 & 100 & 125 & 0 & 930 & 100 & $\ldots$ & 0 \\
\hline Bolivia (Estado Plurinacional de) & 160608 & 96 & 7229 & 4 & 2420 & 100 & $\ldots$ & 0 \\
\hline Brasil & $\ldots$ & $\ldots$ & 381132 & 100 & $\ldots$ & $\ldots$ & $\ldots$ & $\ldots$ \\
\hline Chile & $\ldots$ & $\ldots$ & $\ldots$ & $\ldots$ & $\ldots$ & $\ldots$ & $\ldots$ & $\ldots$ \\
\hline Colombia & 1333290 & 99 & 13999 & 1 & $\ldots$ & $\ldots$ & $\ldots$ & $\ldots$ \\
\hline Ecuador & 100883 & 84 & 19726 & 16 & 39285 & 98 & 633 & 2 \\
\hline México & $\ldots$ & $\ldots$ & $\ldots$ & $\ldots$ & $\ldots$ & $\ldots$ & $\ldots$ & $\ldots$ \\
\hline Paraguay & 6803 & 66 & 3488 & 34 & 370 & 94 & 25 & 6 \\
\hline Perú & 4954 & 63 & 2922 & 37 & 350 & 100 & $\ldots$ & 0 \\
\hline Uruguay & 954 & 4 & 25611 & 96 & 31 & 100 & $\ldots$ & 0 \\
\hline Venezuela (República Bolivariana de) & 55 & 0 & 12143 & 100 & 3 & 100 & $\ldots$ & 0 \\
\hline
\end{tabular}

Fuente: elaboración propia sobre la base de información de las Naciones Unidas, Base de datos estadísticos sobre el comercio de mercaderías (COMTRADE). 
inserción económica internacional de un país, pero si el objetivo es la diversificación (como, de hecho, debería serlo), estos acuerdos deben complementarse con otras

\section{IV}

\section{Conclusiones}

¿Adónde conduce todo esto? Un resumen de los hechos permite constatar que las estrategias de inserción económica internacional de América Latina se han centrado en la firma de ALC y acuerdos preferenciales de comercio. A primera vista, el crecimiento de las exportaciones ha sido alentador, pero cuando se desagregan los datos de dicho incremento surgen varias interrogantes. En primer lugar, si bien se ha registrado un considerable aumento de los socios comerciales y sin duda ha habido un viraje hacia los países asiáticos, la distribución de las cuotas de los cinco principales mercados exportadores se ha mantenido casi constante. Por lo tanto, los países en general han logrado poco en lo que se refiere a la diversificación de los riesgos. En segundo término, la diversificación hacia nuevas exportaciones ha sido decepcionante. En los pocos casos en que los países comenzaron a exportar nuevos productos, se trataba en general de productos básicos que sustituían a otras exportaciones de productos básicos. La estructura de exportaciones de los tres principales productos para cada país se mantuvo mayormente sin cambios, por lo que los países no lograron implementar un cambio estructural en sus economías. El incremento de las exportaciones se atribuye, sobre todo, al crecimiento en el margen intensivo. Si se analizan más detenidamente los índices de concentración se descubren pequeñas mejoras con respecto al número de socios comerciales, pero no con el número de productos. Finalmente, estos resultados se corroboran cuando se cruzan los datos con el crecimiento de las exportaciones y la existencia de ALC: estos acuerdos han sido bastante ineficaces a la hora de promover la diversificación de productos de exportación.

Los ALC, sin el respaldo de otras políticas más integrales, revelan un enfoque de política de laissez-faire. Estos acuerdos no pueden considerarse un elemento de política activa, ya que solo vienen a confirmar prácticas informales existentes y no influyen en nuevos procesos ni los guían. No se ha prestado suficiente atención a los "fundamentos" del país (Hausmann, Hwang y Rodrik, políticas industriales. En palabras de Osvaldo Rosales, ex negociador jefe de Chile, un ALC no garantiza el éxito económico (Malvasio, 2006).
2007), ya que se consideraba que los ALc promoverían la diversificación de las exportaciones independientemente de ellos.

¿El hecho de que América Latina siga dependiendo de las exportaciones primarias se explica únicamente por los ALC? Por supuesto que no. A menudo, los incentivos económicos contingentes pueden ser contraproducentes para la diversificación de las exportaciones, como se observa más claramente en la abrumadora demanda de recursos naturales de China y la apreciación de las monedas nacionales en América Latina. Los ALC no tendrían ningún efecto ante esas fuerzas económicas, aun cuando promuevan la diversificación de las exportaciones. Si bien en este artículo no se busca desentrañar las causas de tal diversificación, es probable que una política industrial amplia y activa tenga más probabilidades de mitigar estos incentivos perversos que los ALC que tienen un menor alcance.

Esto no significa que los ALC no sean necesarios. Hay que reconocer que estos acuerdos ofrecen numerosos beneficios, pero no este en particular, o al menos no sin el respaldo de una estrategia de exportación integral. Un ALC por sí mismo no cambiará la estructura productiva de una economía. A diferencia del ex asesor económico del presidente George H.W. Bush, Michael Boskin, famoso por haber dicho que no importaba si una economía fabricaba chips para computadoras o papas chips, nos asiste el convencimiento de que la calidad del incremento de las exportaciones sí importa y que los ALC no son el medio ideal para tal efecto. Estos acuerdos han resultado útiles para promover las exportaciones de productos existentes a mercados existentes, pero no ayudan a los países a diversificarse hacia nuevos productos y mercados.

En el campo de la formulación de políticas es necesario investigar cómo promover las exportaciones de productos de mayor valor agregado y cómo lograr una distribución más uniforme (dentro de lo razonable) en términos de estructura de las exportaciones y participación de los socios comerciales. Los encargados 
de formular las políticas no deben considerar que todo termine con la firma de nuevos ALC. Esto no significa que deban abandonar la idea del libre comercio, sino que deben centrarse en cómo mejorar las estrategias existentes complementando los ALC vigentes y futuros con otras medidas. Es muy probable que estos acuerdos continúen siendo el principal instrumento para promover el libre comercio mientras la Ronda de Doha siga en punto muerto.

El presente artículo no es más que una primera aproximación al tema. En las investigaciones que se realicen en el futuro se podría incluir un análisis más profundo caso por caso de la relación entre los ALC y la diversificación de las exportaciones, pudiendo agregarse otras variables. La atención podría centrarse en la política de diversificación de las exportaciones y sería conveniente analizar por qué los beneficios de dicha diversificación a largo plazo han sido dejados de lado y se han priorizado las ganancias a corto plazo. Otra interrogante es hasta qué punto las empresas y los gobiernos de América Latina realmente apoyan el libre comercio y, lo que es más importante, por qué tanto los gobernantes como los académicos han defendido el nexo entre los ALC y la diversificación de las exportaciones.

Por el momento, está claro que la política industrial debería dejar de ser un tabú (Rodrik, 2011). Si los países de América Latina pretenden beneficiarse con el aumento del libre comercio mediante, precisamente, los ALC, deben reconocer que dichos beneficios no son automáticos y que las exportaciones también necesitan basarse en una estrategia orientada a los objetivos. Solo el tiempo dirá si el Estado en los países latinoamericanos es el socio ideal para estos efectos.
Agosin, M. (2006), "Trade and growth: why Asia grows faster than Latin America”, IDB Publications, $\mathrm{N}^{\circ}$ 31778, Washington, D.C., Banco Interamericano de Desarrollo.

Banco Mundial (2012), World Development Indicators [en línea] http://dat.worldbank.org/indicator.

Bernama (2007), "At least two more rounds to conclude Malaysia-US FTA", Bernama.com, 12 de enero [en línea] http://www.bernama. com.my/bernama/v3/news_lite.php?id=240893.

Bhagwati, J. (1995), "U.S. trade policy: the infatuation with free trade areas", The Dangerous Drift to Preferential Trade Agreements, J. Bhagwati y A. Krueger (eds.), Washington, D.C., American Enterprise Institute for Public Policy Research.

BMI View (2010), "China-ASEAN FTA: Winners and Losers", 6 de enero [en línea] http://www.allbusiness.com/economy-economicindicators/economic-conditions-recession/13686748-1.html.

Brenton, P. y R. Newfarmer (2009), "Watching more than the Discovery Channel to diversify exports", Breaking into New Markets: Emerging Lessons for Export Diversification, R. Newfarmer, W. Shaw y P. Walkenhorst (eds.), Washington, D.C., Banco Mundial.

Bulmer-Thomas, V. (2003), The Economic History of Latin America since Independence, Cambridge, Cambridge University Press.

Castañeda, J. (2006), "Latin America's left turn", Foreign Affairs, vol. $85, \mathrm{~N}^{\mathrm{o}} 3$.

Chang, H.J. (2012), 23 Things They Don't Tell You about Capitalism, Nueva York, Bloomsbury Press.

DIRECON (Dirección General de Relaciones Económicas Internacionales) (2010), Chile: 20 años de negociaciones comerciales, Santiago de Chile.

Dornbusch, R. y S. Edwards (1991), The Macroeconomics of Populism in Latin America, Chicago, University of Chicago Press.

Edwards, S. (2010), Left Behind: Latin America and the False Promise of Populism, Chicago, University of Chicago Press. (1995), Crisis and Reform in Latin America: from Despair to Hope, Washington, D.C., Banco Mundial.

Evenett, S. y A. Venables (2002), "Export growth in developing countries: market entry and bilateral trade flows", Working Paper, inédito.
Ffrench-Davis, R., O. Muñoz y G. Palma (1996), "Las economías latinoamericanas, 1950-1990”, Historia económica de América Latina, L. Bethell (ed.), Barcelona, Editorial Crítica.

Fishlow, A. y otros (1994), Miracle or Design? Lessons from the East Asian Experience, Washington, D.C., Consejo de Desarrollo de Ultramar.

Hausmann, R., J. Hwang y D. Rodrik (2007), "What you export matters", Journal of Economic Growth, vol. 12, No 1.

Hesse, H. (2008), "Export diversification and economic growth", Working Paper, $\mathrm{N}^{\circ} 21$, Washington, D.C., Banco Mundial.

Kopinak, K. (1996), Desert Capitalism: Maquiladoras in North America's Western Industrial Corridor, Tucson, University of Arizona Press.

La Primera (2012), "Deben promoverse exportaciones agrícolasexcesiva concentración en minerales es un alto riesgo", 16 de enero [en línea] http://exportacionesdeperu.blogspot.com/2012/01/ deben-promoverse-exportaciones.html

Leipziger, D. (2009), "Foreword", Breaking into New Markets: Emerging Lessons for Export Diversification, R. Newfarmer, W. Shaw y P. Walkenhorst (eds.), Washington, D.C., Banco Mundial.

Lynch, David (2010), Trade and Globalization. An Introduction to Regional Trade Agreements, Lanham, Rowman \& Littlefield Publishers.

Malvasio, G. (2006), "No hay TLc que genere beneficios automáticos," El observador, 2 de julio [en línea] http://www.eclac.org/comercio/ agenda/0/25950/ElObservador02julio06_ORosalesEntrevista.pdf

Mejía, J. (2011), Export Diversification and Economic Growth. An Analysis of Colombia's Competitiveness in the European Union's Market, Berlín, Springer Verlag.

Ministerio de Relaciones Exteriores de Chile (2011), "Declaración conjunta del Presidente Sebastián Piñera y el Presidente Barack Obama con ocasión de su visita a Santiago, Chile", 21 de marzo [en línea] http://www.minrel.gob.cl/prontus_minrel/site/ artic/20110321/pags/20110321155528.php

Naciones Unidas (2012), Base de datos estadísticos sobre el comercio de mercaderías (COMTRADE) [en línea] http://comtrade.un.org/db (1975), "Standard international trade classification Revision 2", Statistical Series Papers, No 34, Nueva York. 
Rodríguez, F. y D. Rodrik (1999), "Trade policy and economic growth: a skeptic's guide to the cross-national evidence", NBER Working Paper Series, № 7081, Cambridge, Massachusetts, National Bureau of Economic Research.

Rodrik, D. (2011), The Globalization Paradox: Democracy and the Future of the World Economy, Nueva York, W.W. Norton and Company.

Samen, S. (2010), "A primer on export diversification: key concepts, theoretical underpinnings and empirical evidence", Growth and Crisis Unit, Washington, D.C., World Bank Institute.

Stokes, S. (2001), Mandates and Democracy: Neoliberalism by Surprise in Latin America, Nueva York, Cambridge University Press.

Taylor, L. (1991), "Economic openness. Problems to the century's end", Economic Liberalization: No panacea. The experiences of Latin America and Asia, T. Banuri (ed.), Oxford, Oxford University Press.
Thorp, R. (1998), Progreso, pobreza y exclusión: Una historia económica de América Latina en el siglo XX, Washington, D.C., Banco Interamericano de Desarrollo.

Todaro, M. y S. Smith (2006), Economic Development, Boston, Pearson-Addison Wesley.

Van den Berg, H. y J. Lewer (2007), International Trade and Economic Growth, Nueva York, M.E. Sharpe.

Volpe, C. y S. Milena (2009), "Trade policy and export diversification: what should Colombia expect from the FTA with the United States", IDB Working Paper Series, No 136, Washington, D.C., Banco Interamericano de Desarrollo.

Williamson, J. (ed.) (1990), Latin American Adjustment: How Much Has Happened?, Washington, D.C., Instituto de Economía Internacional.

Yergin, D. y J. Stanislaw (1998), The Commanding Heights. The Battle for the World Economy, Nueva York, Simon \& Schuster. 